\title{
Micromamíferos del Pleistoceno Medio y Pleistoceno Superior en el Valle del Jarama: yacimientos de Valdocarros y HAT (Madrid, España)
}

\author{
Micromammals of the Middle Pleistocene and Late Pleistocene \\ in the Jarama Valley: the sites of Valdocarros and HAT (Madrid, Spain)
}

\author{
C. Sesé ${ }^{1}$, J. Panera², S. Rubio-Jara², A. Pérez-González ${ }^{3}$
}

\begin{abstract}
RESUMEN
Se realiza el estudio de los micromamíferos del yacimiento de Valdocarros, que se localiza en la unidad de Arganda II de la Terraza Compleja de Arganda, en el valle del Jarama (Madrid), y del yacimiento de HAT, que está en la unidad de Arganda IV. Las asociaciones de micromamíferos determinadas en este trabajo en dichos yacimientos son las siguientes: en Valdocarros: erinaceomorfos: Erinaceus europaeus; soricomorfos: Crocidura aff. russula; roedores: Eliomys quercinus, Castor fiber, Apodemus sp., Cricetulus (Allocricetus) bursae, Arvicola aff. sapidus y Microtus brecciensis; y lagomorfos: Oryctolagus cuniculus; y en HAT: soricomorfos: Soricidae indet.; roedores: Eliomys quercinus, Apodemus sp., Arvicola aff. sapidus y Microtus cf. cabrerae; y lagomorfos: cf. Oryctolagus sp. La asociación del yacimiento de Valdocarros, por su composición y por el estadio evolutivo de Microtus brecciensis, se sitúa en el Pleistoceno Medio avanzado pero no final. La presencia de Microtus cf. cabrerae en el yacimiento de HAT hace que se adscriba al Pleistoceno Superior. Ambas asociaciones indican unas condiciones paleoambientales de clima templado y un buen desarrollo de la cobertura vegetal con zonas boscosas y zonas abiertas con vegetación arbustiva, ribereña y praderas.
\end{abstract}

Palabras clave: Micromamíferos, erinaceomorfos, soricomorfos, roedores, lagomorfos, Pleistoceno Medio, Pleistoceno Superior, Madrid, España.

\section{ABSTRACT}

We study the micromammals from the sites of Valdocarros and HAT, located in the lithostratigraphic unit of Arganda II and IV respectively, within the Arganda Complex Terrace, in the Jarama Valley (Madrid, Spain). The micromammal associations of these sites consist of the following taxa: in Valdocarros: Erinaceomorpha: Erinaceus europaeus; Soricomorpha: Crocidura aff. russula; Rodentia: Eliomys quercinus, Castor fiber, Apodemus sp., Cricetulus (Allocricetus) bursae, Arvicola aff. sapidus and Microtus brecciensis; and Lagomorpha: Oryctolagus cuniculus; and in HAT: Soricomorpha: Soricidae indet.; Rodentia: Eliomys quercinus, Apodemus sp., Arvicola aff. sapidus and Microtus cf. cabrerae; and Lagomorpha: cf. Oryctolagus sp. The micromammal assemblage of the Valdocarros site can be placed in the advanced Middle Pleistocene, but not in its end, because of the faunal association and the evolved state of Microtus brecciensis. However, in HAT, the presence of Microtus cf. cabrerae suggests that this site belongs to the Late Pleistocene. Both micromammal assemblages indicate a temperate climate and a well developed vegetation cover, consisting of some forest and also open areas, with shrub-like vegetation and also meadow and riverside vegetation.

Key words: Micromammals, Erinaceomorpha, Soricomorpha, Rodentia, Lagomorpha, Middle Pleistocene, Late Pleistocene, Madrid, Spain.

\footnotetext{
1 Dpto. Paleobiología. Museo Nacional de Ciencias Naturales. C.S.I.C. C/ José Gutiérrez Abascal 2. 28006 Madrid - España. Email: c.sese@mncn.csic.es

2 Departamento de Prehistoria y Arqueología. Universidad Nacional de Educación a Distancia. C/ Senda del Rey 9. 28040 Madrid. Email: joaquin.panera@gmail.com; srubiojara@ hotmail.com

${ }^{3}$ Centro Nacional de Investigación sobre la Evolución Humana (CENIEH). Avenida de la Paz, 28, entreplanta. 09004 Burgos. Email: alfredo.perez@cenieh.es
} 


\section{Introducción}

En el presente trabajo se aborda el estudio de los micromamíferos de los yacimientos de Valdocarros y HAT. Panera et al. (2002 y 2005) dieron a conocer los datos geológicos, arqueológicos y faunísticos preliminares del yacimiento de HAT. Recientemente se han realizado también publicaciones preliminares sobre ambos yacimientos (Panera et al., 2008 a y b 2010).

Aunque en los valles del Jarama y Manzanares se han encontrado muchos restos de grandes mamíferos desde finales del siglo XIX (Soto \& Sesé, 1987; Sesé \& Soto, 2000 y 2002 a y b), es en la segunda mitad del siglo XX cuando se lleva a cabo una excavación metódica y el estudio multidisciplinar en el yacimiento paleolítico del Pleistoceno Medio de Áridos (Santonja et al., 1980), en el que se aplican por primera vez en Madrid las nuevas técnicas de lavado-tamizado de sedimento para obtener microfauna, con el resultado de la obtención de una variada asociación faunística de micromamíferos (López Martínez, 1980 a). Fuera de la Comunidad de Madrid, pero también en la Cuenca del Tajo, en la provincia de Toledo se realiza posteriormente el hallazgo de micromamíferos en los yacimientos del Pleistoceno Medio de Buenavista Inferior y Salchicha Inferior (Sesé et al., 2000). Recientemente, como resultado de la excavación en el yacimiento del Pleistoceno Medio de TAFESA (antigua TRANSFESA), en el sur de la Comunidad de Madrid, se ha obtenido una asociación de mamíferos aunque muy pobre en micromamíferos (Sesé, 2010; Baena et al., 2010).

Creemos, por tanto, que este trabajo viene a cubrir la escasez de datos paleontológicos de micromamíferos que había al sur de la Cuenca de Madrid desde la publicación de Áridos (López Martínez, 1980 a).

\section{Geología, cronología, macromamíferos, industria y ocupación humana de los yacimientos de Valdocarros y HAT}

El yacimiento de Valdocarros (Arganda del Rey, Madrid) se sitúa en el tercio superior de la unidad estratigráfica de Arganda II, y el yacimiento de HAT en el tercio basal de la unidad de Arganda IV (Panera et al., 2005), que a su vez forman parte de la Terraza Compleja de Arganda que llega a alcanzar espesores de hasta 40-50 m en el tramo medio- bajo del valle del río Jarama (Fig. 1). Estas unidades superpuestas se han originado por procesos sinsedimentarios de hundimiento por karst subyacente de las rocas evaporíticas miocenas que forman el sustrato en estos sectores de la Cuenca Terciaria de Madrid (Pérez-González, 1971). El yacimiento de Áridos, anteriormente mencionado, se sitúa en la unidad de Arganda I (Pérez González, 1980). Es decir, que los nuevos yacimientos de Valdocarros y HAT están situados estratigráficamente por encima del yacimiento de Áridos.

En el yacimiento de HAT se dispone de una fecha por luminiscencia de $74+16 /-12,1$ ka BP, lo que lo sitúa a finales del MIS 5 (Panera et al., 2005), mientras que en Valdocarros se están aplicando actualmente técnicas de datación por racemización de aminoácidos y ESR de las que se espera obtener resultados en breve.

En Valdocarros se han identificado tres grandes unidades, que se han denominado de la más antigua a la más moderna Valdocarros I, II y III (Panera et al., 2008 b y 2010). Las unidades de Valdocarros I y III se han interpretado como amplias llanuras de inundación abiertas y alejadas del cauce principal que se fueron colmatando por los sedimentos aportados por desbordamientos periódicos del río. Valdocarros II está formado por varios ambientes sedimentarios, de los que el primero se corresponde con una secuencia de un canal meandriforme que erosiona a Valdocarros I, mientras que el segundo lo hace con el relleno del meandro abandonado. Este relleno se produce únicamente durante los eventos de inundación: los flujos de agua llegan con muy baja energía transportando únicamente sedimentos finos en suspensión. En Valdocarros I y II se han registrado abundantes restos de fauna e industria lítica. Una nueva migración lateral del cauce del río Jarama erosionó Valdocarros II, y nuevas riadas volvieron a rellenar este hueco, hasta su colmatación, con depósitos limoarcillosos que constituyen Valdocarros III donde no se han hallado vestigios arqueopaleontológicos.

La intervención arqueológica se centró en Valdocarros II. Ante la baja densidad y relativa dispersión de los materiales, se adoptó como estrategia la excavación de una gran superficie que permitiera interpretar espacialmente las actividades humanas realizadas en el yacimiento. Se excavaron $836 \mathrm{~m}^{2}$, donde se diferenciaron cuatro niveles de inundación (numerados del 1 al 4 de muro a techo), situados por encima del nivel 0 , todos con industria lítica y fauna. 

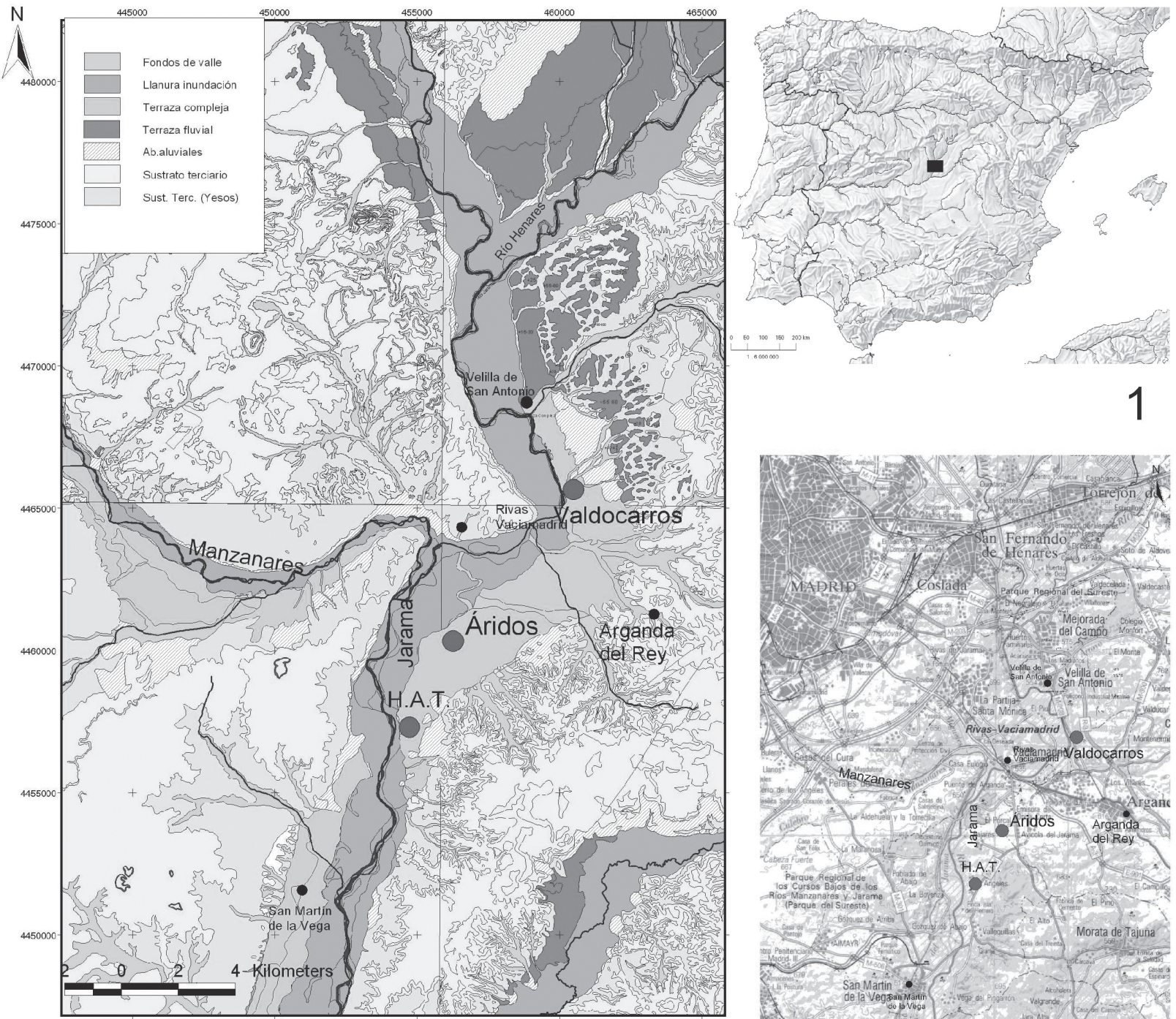

3
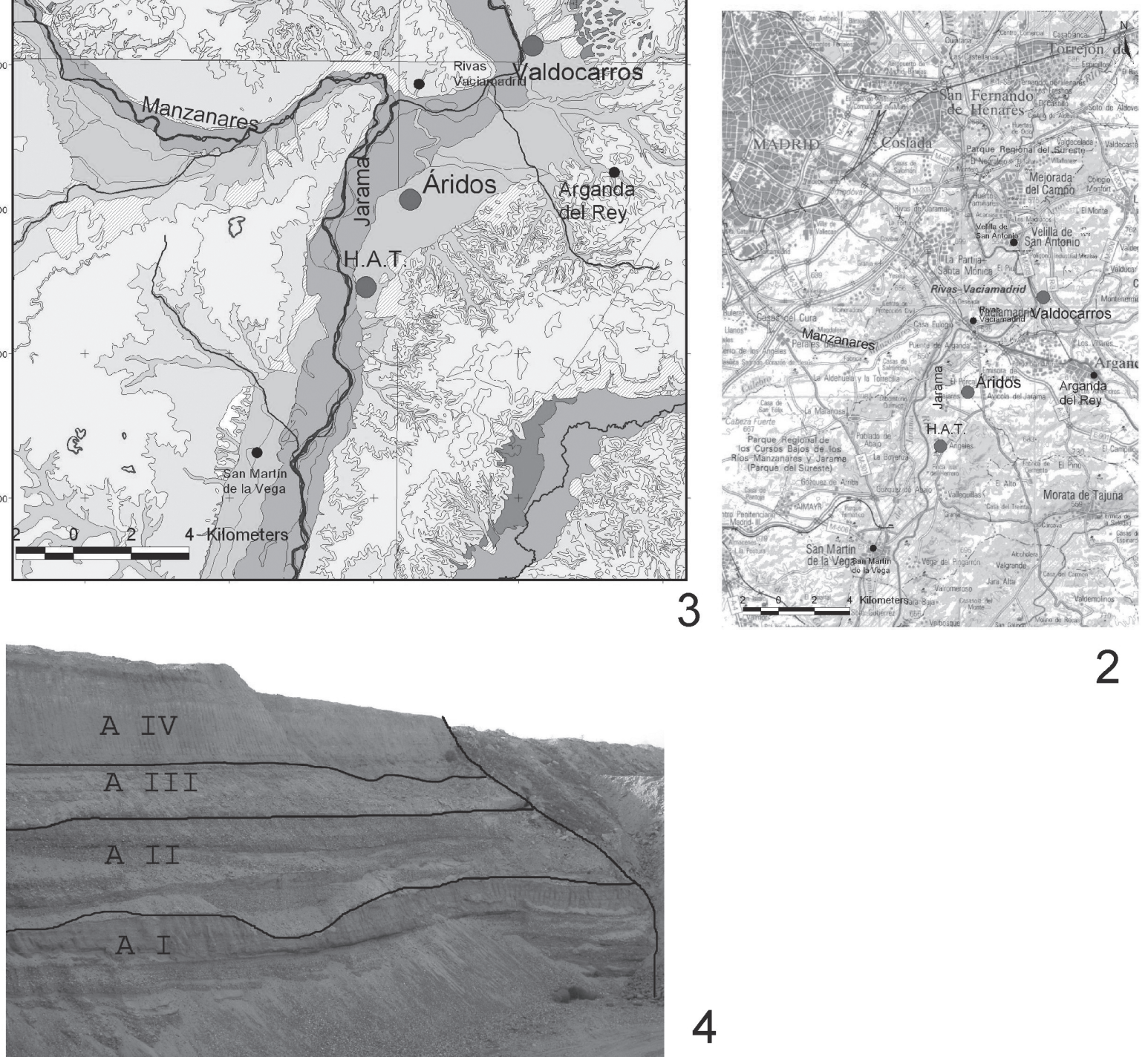

Fig. 1.-1 y 2: Localización del área de estudio; 3: Proyección de los yacimientos de Valdocarros y HAT sobre el mapa geomorfológico simplificado de las hojas geológicas del IGME (Calvo et. al., 1989; Portero et al., 1990; San José, 1975; Vegas et al., 1975); 4: Unidades de la Terraza Compleja de Arganda en Valdocarros. 
Se han recuperado unos 2.750 restos óseos de grandes mamíferos. El $71 \%$ de los mismos son fragmentos no identificables (el 79\% de las piezas tiene menos de $3 \mathrm{~cm}$ ). Cervus elaphus es la especie con más número de restos, seguida por Equus caballus, Bos primigenius y en menor medida los cérvidos de pequeño tamaño (corzo, gamo), Capreolus sp., Dama sp. y Elephas sp. (Yravedra \& DomínguezRodrigo, 2008). Finalmente hay un reducido número de restos de carnívoros como Felix sp., Canis lupus o Vulpes vulpes. Cabe destacar una pequeña tibia de zorro que presenta marcas de corte que sugieren actividades complementarias: así las situadas en torno a la epífisis distal indican desarticulado y las de la diáfisis descarnado (Yravedra, 2007). La presencia de este tipo de marcas de corte en restos de carnívoros es inusual en el registro arqueológico anterior al Pleistoceno Superior.

Yravedra \& Domínguez-Rodrigo (2008) han realizado un análisis preliminar sobre la significación de los perfiles esqueléticos documentados en este yacimiento. Un conjunto con una representación esquelética dominada por elementos craneales y metápodos, es susceptible de indicar un comportamiento carroñero (Vrba, 1980; Binford, 1981 y 1984; Stiner, 1994). En Valdocarros (incluyendo las diáfisis en la determinación de piezas), los húmeros y los fémures son los elementos más numerosos, lo que unido a la presencia de marcas de cortes en las zonas de los huesos con mayor potencial cárnico, lleva a considerar a Yravedra \& Domínguez-Rodrigo (2008) que los homínidos fueron el principal agente de acumulación de todo el registro óseo de macromamíferos. Dichos autores (o.c.) también han estimado el grado de transporte de las carcasas animales a partir de los métodos propuestos por Faith \& Gordon (2007), llegando a la conclusión de que las diferentes presas fueron aportadas al yacimiento prácticamente completas y desde distancias cortas.

La industria lítica es Achelense y sus características tecnológicas fundamentales coinciden con las observadas en otros conjuntos achelenses de la Meseta (Panera, 2009). En Valdocarros I y II se realizaron actividades de talla, que están principalmente en relación con la reducción de núcleos y en algunos niveles con la configuración y el reavivado de bifaces. Se han hallado 3.009 piezas líticas talladas y 1.119 cantos. Unas dos terceras partes de las piezas son de sílex, menos de una tercera parte de cuarcita y el resto de cuarzo. Los esquemas operativos de producción identificados en los núcleos ponen de manifiesto que en la cuarcita prevalecen las cadenas operativas cortas (unifaciales y bifaciales), mientras que en el sílex se desarrollan cadenas operativas más largas (multifaciales y discoides). El empleo del esquema levallois es marginal y está mejor representado por lascas que por núcleos. Raederas, lascas retocadas y denticulados, son los morfotipos retocados más característicos. En los esquemas operativos de configuración predominan los bifaces con más de la mitad de los efectivos, mientras que los cantos trabajados están mucho mejor representados que hendedores y sobre todo que triedros, que son escasos.

En el yacimiento de Valdocarros se ha documentado la ocupación reiterada de grupos humanos del medio fluvial a lo largo de unos siglos o incluso milenios, motivada por la combinación de la cercanía del canal principal de un río de cierta envergadura, como es el Jarama (tributario del Tajo), y del «abrigo» que proporcionó el escarpe del borde de la llanura de inundación en Valdocarros I, o la depresión en la llanura de inundación del meandro abandonado en Valdocarros II. El valle del Jarama en estos momentos estuvo frecuentado por herbívoros atraídos por su vegetación y proximidad al agua, algún carnívoro, y grupos de homínidos. La mayoría de los yacimientos al aire libre del Pleistoceno Medio en la Península Ibérica obedecen a actividades concretas realizadas por los homínidos de este período: aprovechamiento de la carcasa de grandes mamíferos (Áridos I y II, Santonja et al., 1980; Ambrona, Villa et al., 2005) o elaboración de útiles líticos (Soto e Hijos en Baena, 1992). Valdocarros es un modelo de yacimiento diferente, donde se dispone de una de las mayores superficies con restos arqueológicos del Pleistoceno en la Península Ibérica, que podría estar entre 1 y $2 \mathrm{Ha}$.

HAT es un yacimiento en facies de llanura de inundación donde se excavaron dos sondeos con una superficie total de unos $6 \mathrm{~m}^{2}$ y un volumen de $8,55 \mathrm{~m}^{3}$ (Panera et al., 2005). El depósito lacustre en el que se encontraba el yacimiento se observaba a lo largo de unos $60 \mathrm{~m}$ en la base de la unidad Arganda IV, formada por depósitos distales de abanicos aluviales y depósitos lacustres someros, que en este sector presenta una potencia de $19 \mathrm{~m}$ (Panera et al., 2005).

Se documentaron restos de microvertebrados, un molar de Equus caballus, y 60 piezas líticas (incluyendo los debris recogidos en el residuo del triado del sedimento levigado), lo que implica una densidad de 6 piezas líticas por $\mathrm{m}^{2}$ ó 7 por $\mathrm{m}^{3}$ (Panera et al., 2005). 
En la industria lítica, el sílex es la materia prima dominante con más de dos terceras partes de la muestra, seguida por la cuarcita, y el cuarzo; las piezas presentan sus aristas frescas; están presentes todos los elementos de la cadena operativa lítica, aunque en porcentajes que no corresponderían a una muestra completa; y el macroutillaje está representado sólo por un canto trabajado, que fue usado en una primera fase como percutor (Panera et al., 2005).

La escasa superficie excavada únicamente permite señalar que se trata de un lugar hasta el que se trasladaron materias primas, y en el que parece hubo actividades de talla y aprovechamiento de fauna (Panera et al., 2005).

\section{Metodología}

Ante la imposibilidad de levigar todo el sedimento obtenido de las excavaciones se optó por hacer un muestreo estadístico. En Valdocarros se recogieron 795 muestras de sedimento de unos $30 \mathrm{~kg}$ cada una (23.850 kg en total) y en HAT 27 muestras también de unos $30 \mathrm{~kg}$ cada una $(810 \mathrm{~kg})$, distribuidas en ambos casos por toda el área excavada. De cada una de estas muestras se anotaron sus tres coordenadas espaciales. Además, durante el proceso de excavación, cada vez que de visu se distinguían restos de microvertebrados, se recogía a su alrededor una muestra de sedimento de $2-5 \mathrm{~kg}$ registrando también sus coordenadas espaciales, lo que se realizó en 286 ocasiones en Valdocarros y en dos ocasiones en HAT. Por este procedimiento en Valdocarros se recuperaron buena parte de los restos de conejo y castor.

Los restos fósiles de micromamíferos de este último yacimiento proceden en su totalidad de los cinco niveles de Valdocarros II. En los pocos casos en los que alguno de ellos no se ha podido asignar a un nivel concreto, se señala en el texto como: Nivel sin especificar (N.s.e.).

El sedimento recogido se sometió al método de lavado-tamizado, mediante su disgregación, eliminando la matriz arcilloso-limosa y obteniendo un concentrado enriquecido en restos fósiles. En primer lugar se procedió al secado de las muestras, a continuación se sumergieron en agua para facilitar su disgregación, y finalmente se lavaron con agua a presión en una mesa con un juego de dos tamices, uno de $2 \mathrm{~mm}$ y otro $0,5 \mathrm{~mm}$ de luz de malla, que asegura la retención de las piezas fósiles más pequeñas y la eliminación de la fracción arcillosa del sedimento. Una vez obtenido el concentrado en distintas fracciones de cada muestra, se procedió a triar de visu la totalidad del sedimento conseguido en la criba con luz de malla de $2 \mathrm{~mm}$, y, utilizando una lupa binocular, se triaron las muestras procedentes de la criba con luz de malla de $0,5 \mathrm{~mm}$ con mayor potencialidad para obtener restos fósiles de microvertebrados de menor talla (40 de las muestras del yacimiento de Valdocarros y 6 del yacimiento de HAT).

Casi todos los taxones de micromamíferos se han comparado con material actual de los mismos de las colecciones del Museo Nacional de Ciencias Naturales. En el apartado de descripción y discusión, como es habitual en la paleontología sistemática, los taxones de los yacimientos que se estudian en este trabajo se han comparado con los datos publicados sobre los micromamíferos de otros yacimientos pleistocenos en los que éstos están suficientemente descritos morfológica y biométricamente y que por lo tanto permiten su utilización a todos los efectos. Los dientes se han medido utilizando una lupa que lleva incorporada un micrómetro de $0,025 \mathrm{~mm}$ de precisión. Las medidas se han tomado en la superficie oclusal de los dientes orientados en su correspondiente posición anatómica, se expresan en milímetros y corresponden a la longitud (L) y anchura (A) máximas. Cuando el diente está roto o desgastado, las medidas se dan entre paréntesis para indicar que son aproximadas y mínimas. Se da también la variabilidad de las dimensiones de la talla para cada rango de molar (dónde $\mathrm{N}$ es el número de ejemplares), con los valores máximos (Máx.), medios (Med.) y mínimos (Mín.). La nomenclatura utilizada para el estudio de los dientes es la de López Martínez (1980 a). Los dientes de micromamíferos se han dibujado empleando una cámara clara acoplada a una lupa binocular y posteriormente se les ha aplicado un tratamiento informático. Para comparar la abundancia relativa de los taxones se ha utilizado el NMI (Número Mínimo de Individuos).

\section{Paleontología sistemática}

Orden Erinaceomorpha GREGORY, 1910 - Erinaceomorfos

Familia Erinaceidae FISCHER, 1814 - Erinaceidos

Subfamilia Erinaceinae FISCHER, 1814 - Erinaceinos

Erinaceus europaeus LINNAEUS, 1758 - Erizo europeo 


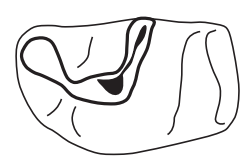

1
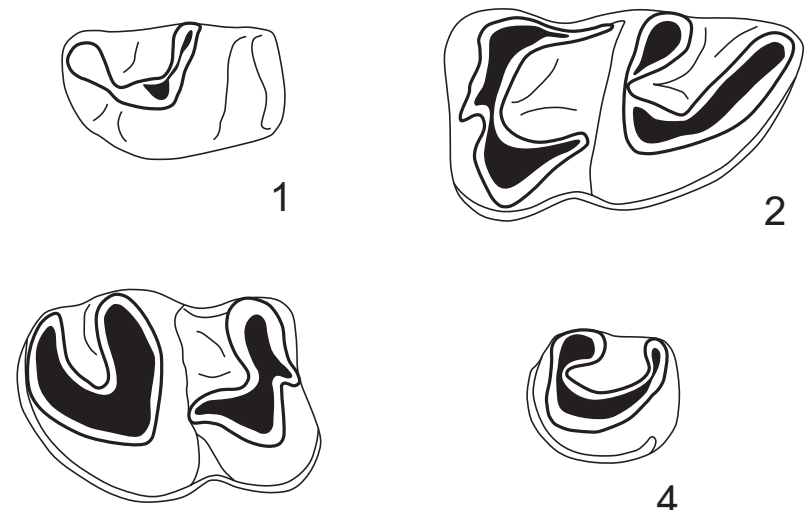

3

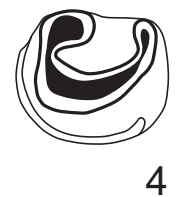

$5 \mathrm{~mm}$

Fig. 2-Yacimiento de Valdocarros: Erinaceus europaeus LINNAEUS, 1758: 1: $\mathbf{P}_{\mathbf{4}}$ izq. (Nivel 3; 91; 47-1); 2 : $\mathbf{M}_{\mathbf{1}}$ der. (Nivel 3; 91; 47-2); 3: $\mathbf{M}_{\mathbf{2}}$ izq.; (Nivel 3; 91; 47-5); $\mathbf{4}: \mathbf{M}_{3}$ der. (Nivel 3; $91 ; 47-6)$.

Yacimiento: Valdocarros

Material:

- Nivel 3: $1 \mathrm{P}_{4}$ izq.; $1 \mathrm{M}_{1}$ izq.; $1 \mathrm{M}_{2}$ izq.; $1 \mathrm{M}_{1}$ der.; $1 \mathrm{fr}$. $M_{1}$ der.; $1 M_{2}$ der.; 1 fr. $M_{2}$ der.; $1 M_{3}$ der.; 1 fr. $M^{1}$ der.; 1 fr. $\mathrm{M}^{2}$ der.; 2 fr. mandíbulas izq. con alveolos de premolares y molares; 1 fr. mandíbula der. con alveolos de premolares y molares. Gran parte del material apareció asociado y corresponde a dos individuos. $\mathrm{NMI}=2$

Medidas:

\begin{tabular}{|c|c|c|c|c|c|c|c|c|}
\hline \multirow[b]{2}{*}{ Diente } & \multirow[b]{2}{*}{$\mathrm{N}$} & \multicolumn{3}{|c|}{ Longitud } & \multirow[b]{2}{*}{$\mathrm{N}$} & \multicolumn{3}{|c|}{ Anchura } \\
\hline & & Mín. & Med. & Máx. & & Mín. & Med. & Máx. \\
\hline $\mathrm{P}_{4}$ & 1 & - & 3,92 & - & 1 & - & 2,58 & - \\
\hline $\mathrm{M}_{1}$ & 2 & 6,26 & 6,28 & 6,29 & 2 & 3,96 & 3,96 & 3,97 \\
\hline $\mathrm{M}_{2}$ & 2 & 5,66 & 5,73 & 5,80 & 2 & 4,05 & 4,12 & 4,20 \\
\hline $\mathrm{M}_{3}$ & 1 & - & 2,56 & - & 1 & - & 2,46 & - \\
\hline
\end{tabular}

\section{Descripción y discusión:}

Comparado con material actual de la especie es similar en talla y morfología.

Erinaceus europaeus se registra en España desde el final del Pleistoceno Inferior en el nivel TD4 de Gran Dolina de Atapuerca (Gil, 1986; Sesé, 1994).

En la actualidad esta especie se encuentra ampliamente distribuida en prácticamente toda la Península Ibérica, aunque en las zonas mediterráneas más áridas es más escasa hasta desaparecer. Es una especie que vive en zonas húmedas y con cobertura vegetal, tanto en bosques como, más frecuentemente, en zonas de borde de bosque, e incluso en zonas abiertas pero con vegetación arbustiva (Blanco, 1998; Palomo \& Gisbert, 2002; Sesé, 2005).
Orden Soricomorpha GREGORY, 1910 - Soricomorfos

Familia Soricidae FISCHER, 1814 - Sorícidos Crocidura aff. russula (HERMANN, 1780) Musaraña gris

(Fig. 3: 1-3)

Yacimiento: Valdocarros

Material:

- Nivel 1: $1 \mathrm{M}_{2}$ der.; 1 fr. $\mathrm{P}^{4}$ der.; 1 fr. $\mathrm{M}^{1}$ der.; $\mathrm{NMI}=1$

- Nivel 3: 1 fr. mandíbula izq. con fr. $\mathrm{M}_{2}$ y $\mathrm{M}_{3} ; 1$ fr. $\mathrm{M}_{1-2}$ der.; 1 fr. $\mathrm{M}^{1-2}$ der.; NMI = 1

- Nivel 4: $1 \mathrm{M}_{3}$ der.; 1 fr. $\mathrm{M}^{1}$ der.; $\mathrm{NMI}=1$

NMI Total de todos los Niveles $=3$

\section{Medidas:}

$1 \mathrm{M}_{2}: \mathrm{L}=1,38 ; \mathrm{A}=0,92 ; 2 \mathrm{M}_{3}$ : L: Mín. = 1,0; Med. = 1,01; Máx. =1,02; A: Mín. =0,52; Med. =0,57; Máx. =0,62

\section{Descripción y discusión:}

La morfología de este material es similar a la de Crocidura russula: así, el $\mathrm{M}_{3}$ presenta el talónido muy reducido, como sucede en dicha especie; sin embargo, casi todos los dientes de Valdocarros tienen una talla algo menor que las poblaciones actuales de la especie, como sucede en la población de Crocidura aff. russula del yacimiento de Áridos (López Martínez, 1980 a).

La especie Crocidura russula se registra en España desde el Pleistoceno Medio avanzado (Sesé, 1994; Sesé \& Sevilla, 1996), en yacimientos como Áridos (López Martínez, 1980 a) y El Higuerón o Rincón de la Victoria (López Martínez, 1972).

En la actualidad se distribuye ampliamente por toda la España peninsular excepto en zonas de gran altitud.

Es una especie termófila con requerimientos mediterráneos que se asocia a zonas de bosque no muy denso, preferentemente a bordes de bosque y zonas abiertas de matorral y pradera (Blanco, 1998; Palomo \& Gisbert, 2002; Sesé, 2005).

\section{Soricidae indet.}

Yacimiento: HAT

\section{Material:}

1 fragmento de mandíbula izq. de la que sólo se conserva parte de la rama horizontal con el alveolo del tercer molar y el arranque de la rama ascendente rota; $\mathrm{NMI}=1$

\section{Descripción y discusión:}

Su talla y morfología son las características de los sorícidos, pero el escaso material no permite una mayor precisión taxonómica.

Orden Rodentia BOWDICH, 1821 - Roedores Suborden Sciuromorpha BRANDT, 1855 - Esciuromorfos

Familia Gliridae MUIRHEAD, 1819 - Glíridos

Eliomys quercinus (LINNAEUS, 1766) - Lirón careto

(Fig. 3: 4) 


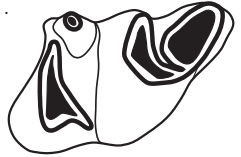

1

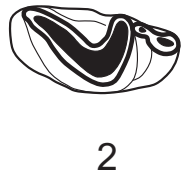

2

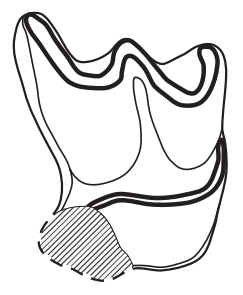

3

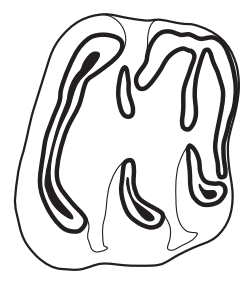

4

$1 \mathrm{~mm}$

Fig. 3.-Yacimiento de Valdocarros: Crocidura aff. russula (HERMANN, 1780): 1: $\mathbf{M}_{2}$ der. (Nivel 1; $\mathbf{M - 1 5 6 ; 8 3 - 1 ) ; ~ 2 : ~} \mathbf{M}_{3}$ izq. (Nivel 4; M-315; 75-1); 3: fr. $\mathbf{M}^{1}$ der. (Nivel 4; M-315; 75-2); Eliomys quercinus (LINNAEUS, 1766): $4: \mathbf{M}_{2}$ der. (Nivel 2: M-41; 78-1).

Yacimiento: Valdocarros

Material y medidas:

- Nivel 2: $1 \mathrm{P}^{4}$ der.: $\mathrm{L}=1 ; \mathrm{A}=1,13 ; 1 \mathrm{M}_{2}$ der.: $\mathrm{L}=1,40$; $\mathrm{A}=1,55 ; \mathrm{NMI}=1$

\section{Descripción y discusión:}

Este material es de morfología similar a las poblaciones actuales de dicha especie y a la del yacimiento del Pleistoceno Medio de Áridos (López Martínez, 1980 a), aunque su talla es algo más pequeña que las poblaciones actuales.

Aunque la especie Eliomys quercinus aparece citada en las listas faunísticas de algunos yacimientos del final del Plioceno y Pleistoceno Inferior (Agustí \& Galobart, 1986), la especie que se registra con frecuencia en los yacimientos del Pleistoceno Inferior es Eliomys intermedius (Sesé, 1994; Arribas, 2004), mientras que el registro de Eliomys quercinus es común desde el final del Pleistoceno Inferior y transición del Pleistoceno Inferior al Pleistoceno Medio (Sesé, 1994; Sesé \& Sevilla, 1996; Arribas, 2004), en yacimientos como Huéscar 1 (Mazo et al., 1985), los distintos niveles de Sima del Elefante de Atapuerca (Laplana \& Cuenca-Bescós, 2000; Made et al., 2003) y algunos de los niveles inferiores de Gran Dolina de Atapuerca (Gil, 1986; Sesé \& Gil, 1987).

En la actualidad está ampliamente distribuida en la España peninsular e Islas Baleares. Es una especie endémica europea que está prácticamente confinada al oeste europeo, mientras que en el noreste hay solo algunas poblaciones dispersas (Mitchell-Jones et al., 1999).

Aunque no es una especie estrictamente forestal, suele vivir en zonas boscosas así como también en zonas abiertas arbustivas e incluso pedregosas pero rodeadas de vegetación (Blanco, 1998; Palomo \& Gisbert, 2002; Sesé, 2005). Chaline (1972) señala que, dada su distribución actual europea en la que su frecuencia disminuye hacia el norte, su presencia en el Pleistoceno podría estar asociada a un desarrollo forestal en un clima templado.
Yacimiento: $H A T$

Material y medidas:

$$
1 \mathrm{P}^{4} \text { izq.: } \mathrm{L}=(1,16) ; \mathrm{A}=(1,50) ; \mathrm{NMI}=1
$$

Descripción y discusión:

Aunque el premolar está muy erosionado, se distinguen bien las cúspides principales: dos labiales y una lingual, así como las crestas transversales y la ligera concavidad de la superficie oclusal del diente. En una comparación con material actual de la especie muestra la misma morfología y talla. La talla entra dentro de la variabilidad de la población de dicha especie del yacimiento de Áridos, según López Martínez (1980 a).

\section{Suborden Castorimorpha WOOD, 1955 - Castori- morfos \\ Familia Castoridae HEMPRICH, 1820 - Castóridos Castor fiber LINNAEUS, 1758 - Castor europeo} (Fig. 4)

\section{Yacimiento: Valdocarros}

\section{Material:}

- Nivel 2: 1 fr. I inf.; $1 \mathrm{P}_{4}$ izq.; $1 \mathrm{M}_{1}$ izq. en fr. mandibular; 1 fr. $\mathrm{M}_{2}$ izq. $\mathrm{y}$ varios fr. mandibulares (todo este material apareció asociado y corresponde al mismo individuo); 1 fr. $\mathrm{P}_{4}$ izq.; 1 $M_{1}$ izq.; 1 fr. $M_{2}$ izq. y varios fr. mandibulares, entre otros, de la rama ascendente (todo este material apareció asociado y corresponde al mismo individuo); $1 \mathrm{M}^{3}$ der. asociado a varios fr. maxilar; 1 fr. $\mathrm{M}$ indet.; $\mathrm{NMI}=2$.

\section{Medidas:}

$1 \mathrm{P}_{4}: \mathrm{L}=7,46 ; \mathrm{A}=6,53 ; 1 \mathrm{M}_{1}: \mathrm{L}=7 ; \mathrm{A}=(6,83) ; 1 \mathrm{M}_{1}: \mathrm{L}=$ $(7,4) ; \mathrm{A}=(7,1) ; 1 \mathrm{M}_{2}: \mathrm{L}=6,94 ; \mathrm{A}=(6,94) ; 1 \mathrm{M}_{2}: \mathrm{L}=(7,43)$; $\mathrm{A}=(7,07) ; 1 \mathrm{M}^{3}: \mathrm{L}=5,66 ; \mathrm{A}=5,94$

\section{Descripción y discusión:}

Este material presenta la morfología característica de la especie. La talla entra dentro de la variabilidad de la de las poblaciones actuales de Castor fiber según Stefen (2009), próxima a los valores mínimos.

Castor fiber se registra en España desde uno de los niveles inferiores de Gran Dolina de Atapuerca (Gil, 1986) y algunos niveles de Sima del Elefante de Atapuerca del final del Pleistoceno Inferior (Laplana \& Cuenca-Bescós, 2000; Made et al., 2003). Estuvo ampliamente distribuida por toda la Península Ibérica durante el resto del Pleistoceno y Holoceno hasta tiempos históricos (Sesé \& Soto, 1981; Antunes, 1989; Sesé, 1994; Álvarez et al., 1992). Su registro fósil más reciente en España se ha realizado en niveles tardorromanos datados entre los siglos IV y VI (Arribas, 2004), aunque su extinción puede haber sido más tardía.

En este sentido, y con todas las reservas que supone el no tener un registro de la especie fósil o subfósil posterior a estas fechas, parece haber referencias escritas de la presencia del castor en España en la Edad Media durante la época musulmana en relación al río Ebro (Bramon Planas, 1989), de topónimos y otros escritos en Portugal durante la Edad Media hasta la primera mitad del siglo XV (Antunes, 1989), hasta las notas que al parecer realizó el naturalista suizo Konrad von Gesner sobre España en 1583 (en: Brehm, 1891, según Veron, 1992). Este 


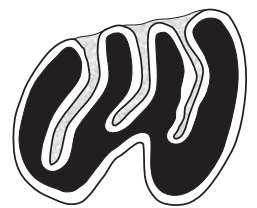

1

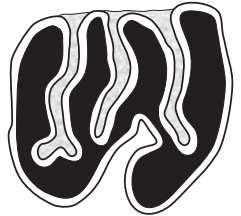

2

$5 \mathrm{~mm}$
Fig. 4.-Yacimiento de Valdocarros: Castor fiber LINNAEUS, 1758: 1: $\mathbf{P}_{4}$ izq. (Nivel 2; 603; 7-2); 2: $\mathbf{M}_{\mathbf{1}}$ izq. (Nivel 2; 603; 7-1); 3: $\mathbf{M}^{3}$ der. (Nivel 2; 3275; 8-1).

último autor (o.c.), aunque en efecto señala la persistencia del castor en la Península Ibérica incluso en el siglo XVI (Veron, 1992: Fig. 3), quizás apoyándose en el último testimonio escrito antes mencionado, indica que podría haber desaparecido mucho antes, ya que no hay prácticamente testimonios fiables. Así pues todas estas referencias son poco rigurosas, ya que no han podido ser contrastadas, y por lo tanto no tienen valor.

El castor europeo, muy extendido en gran parte de Eurasia durante el Pleistoceno y Holoceno, vio reducidas sus poblaciones especialmente en tiempos históricos hasta quedar limitada su distribución en Europa, al comienzo del siglo XX, a unos pocos enclaves en algunos de los principales ríos europeos, como el Ródano en Francia y el Elba en Alemania, también en el sur de Noruega, Polonia, y algunas poblaciones aisladas en Bielorrusia, Ucrania, Rusia y Mongolia, aunque estas poblaciones se han mantenido y desde mediados del siglo XX han servido de base para su reintroducción con éxito en varios países europeos (Veron, 1992; Kautenburger \& Sander, 2008).

El castor es un roedor ripícola que vive actualmente en la ribera de arroyos y ríos y al borde de lagos en los que hay agua durante todo el año y vegetación boscosa alrededor (MitchellJones et al., 1999).

Suborden Myomorpha BRANDT, 1855 - Miomorfos Superfamilia Muroidea ILLIGER, 1811 - Muroideos Familia Muridae ILLIGER, 1811 - Múridos Subfamilia Murinae ILLIGER, 1811 - Murinos

Apodemus sp. - Ratón

(Fig. 5: 1-5 y Fig. 7: 1-3)

Yacimiento: Valdocarros

Material:

\begin{tabular}{|c|c|c|}
\hline Nivel & Material & NMI \\
\hline 1 & $\begin{array}{l}1 \text { fr. mandíbula der. con } \mathrm{I}-\mathrm{M}_{1}-\mathrm{M}_{2} ; 1 \mathrm{fr} \text {. } \\
\text { mandíbula der. con } \mathrm{M}_{1 ;} 1 \mathrm{fr} \text {. mandíbula izq. } \\
\text { con } \mathrm{M}_{1}-\mathrm{M}_{2} ; 1 \text { fr. mandíbula izq. con } \mathrm{M}_{1} \text {; } \\
1 \mathrm{M}_{1} \text { der.; } 2 \mathrm{M}_{2} \text { der.; } 1 \mathrm{M}_{2} \text { izq.; } 1 \mathrm{M}_{3} \text { der.; } \\
1 \mathrm{M}_{3} \text { izq.; } 1 \mathrm{M}^{2} \text { izq. }\end{array}$ & 3 \\
\hline 2 & $\begin{array}{l}1 \mathrm{M}_{1} \text { der.; } 1 \text { fr. } \mathrm{M}_{1} \text { der.; } 2 \mathrm{M}_{1} \text { izq.; } 2 \mathrm{M}_{2} \text { der.; } \\
2 \mathrm{M}_{2} \text { izq.; } 1 \mathrm{M}^{1} \text { der.; } 1 \mathrm{M}^{2} \text { der.; } 1 \mathrm{M}^{3} \text { izq. }\end{array}$ & 2 \\
\hline 3 & $\begin{array}{l}1 \text { fr. } M_{1} \text { der.; } 1 \text { fr. } M_{1} \text { izq.; } 1 \text { fr. } M_{3} \text { der.; } 1 \text { fr. } \\
\text { maxilar der. con } M^{1} ; 1 M^{2} \text { der.; } 1 M^{3} \text { der. }\end{array}$ & 1 \\
\hline Total 1-3 & & 6 \\
\hline
\end{tabular}

Medidas:

\begin{tabular}{|c|c|c|c|c|c|c|c|c|}
\hline \multirow[b]{2}{*}{ Diente } & \multirow[b]{2}{*}{$\mathrm{N}$} & \multicolumn{3}{|c|}{ Longitud } & \multirow[b]{2}{*}{$\mathrm{N}$} & \multicolumn{3}{|c|}{ Anchura } \\
\hline & & Mín. & Med. & Máx. & & Mín. & Med. & Máx. \\
\hline $\mathrm{M}_{1}$ & 8 & 1,60 & 1,72 & 1,91 & 8 & 0,98 & 1,04 & 1,11 \\
\hline $\mathrm{M}_{2}$ & 9 & 1,16 & 1,22 & 1,27 & 9 & 1,04 & 1,06 & 1,12 \\
\hline $\mathrm{M}_{3}$ & 2 & 0,90 & 0,92 & 0,95 & 2 & 0,83 & 0,86 & 0,89 \\
\hline $\mathbf{M}^{1}$ & 2 & 1,83 & 1,86 & 1,89 & 2 & 1,15 & 1,17 & 1,19 \\
\hline $\mathrm{M}^{2}$ & 3 & 1,26 & 1,28 & 1,31 & 3 & 1,03 & 1,06 & 1,08 \\
\hline $\mathrm{M}^{3}$ & 2 & 0,90 & 0,90 & 0,90 & 2 & 0,82 & 0,83 & 0,84 \\
\hline
\end{tabular}

\section{Descripción y discusión:}

La talla de este material entra dentro de la variabilidad de la de las poblaciones de Apodemus cf. sylvaticus de los yacimientos de Cúllar de Baza I (Ruiz Bustos \& Michaux, 1976) y Áridos (López Martínez, 1980 a) y de la de las poblaciones actuales de dicha especie (Pasquier, 1974). Las poblaciones de Apodemus sylvaticus de Pinilla del Valle (Toni \& Molero, 1990), Apodemus cf. sylvaticus de Cueva del Agua (López Martínez \& Ruiz Bustos, 1977) y Apodemus cf. flavicollis de las Yedras (López Martínez \& Ruiz Bustos, 1977), así como las poblaciones actuales de Apodemus flavicollis (Pasquier, 1974), tienen una talla mayor que la de Valdocarros.

La diferenciación entre las especies de talla media, Apodemus sylvaticus (LINNAEUS, 1758) y Apodemus flavicollis (MELCHIOR, 1834), es difícil. Pasquier (1974) y Michaux \& Pasquier (1974) separan ambas especies en poblaciones numerosas por la longitud relativa de los $\mathrm{M}_{2}$ y $\mathrm{M}^{2}$ (relación entre la longitud y la anchura: L/A) y la frecuencia del morfotipo con T9 reducido en el $\mathbf{M}^{2}$. En la primera especie la relación L/A es menor y es menos frecuente el morfotipo reducido del T9 en el $\mathrm{M}^{2}$. En la población de Valdocarros, los valores medios de la relación $\mathrm{L} / \mathrm{A}$ del $\mathrm{M}_{2}$ y $\mathrm{M}^{2}$ son respectivamente de 1,15 y 1,20, valores relativamente altos que en principio le aproximarían a la segunda especie; $\mathrm{y}$, de los 3 ejemplares que hay de $\mathrm{M}^{2}$ solo uno tiene T9 ligeramente reducido, lo que le asemejaría a la primera especie. Sin embargo, teniendo en cuenta que el material del múrido de Valdocarros es muy escaso, especialmente por lo que concierne al número de $\mathrm{M}^{2}$, cuyas características son las más relevantes a nivel taxonómico, no es posible realizar la atribución específica del mismo.

En España Apodemus sylvaticus se cita desde el final del Plioceno y Pleistoceno Inferior, y Apodemus flavicollis desde el final del Pleistoceno Inferior en los niveles inferiores de Gran Dolina de Atapuerca (Gil, 1986; Sesé, 1994; Sesé \& Sevilla, 1996).

Actualmente, mientras que Apodemus sylvaticus (ratón de campo) es uno de los mamíferos más abundantes y está presente en toda la España peninsular, la distribución de Apodemus flavicollis (ratón leonado) se restringe al tercio norte peninsular.

Apodemus sylvaticus vive preferentemente en zonas con una buena cobertura vegetal, bien sea arbustiva o arbórea, mientras que Apodemus flavicollis es una especie típicamente forestal (Blanco, 1998; Palomo \& Gisbert, 2002). Se considera al género Apodemus en general como un indicador termófilo y forestal durante el Pleistoceno, ya que parece que fue más abundante en los periodos relativamente más benignos, en los que estaba asociado a otras especies de medios boscosos, mientras que era 


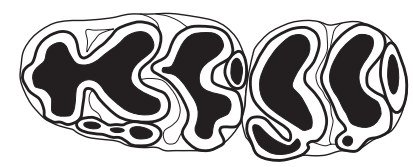

1

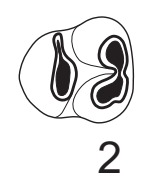

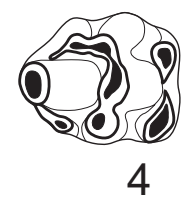

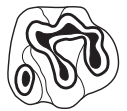

5

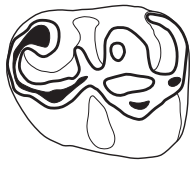

7

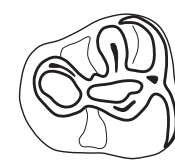

8

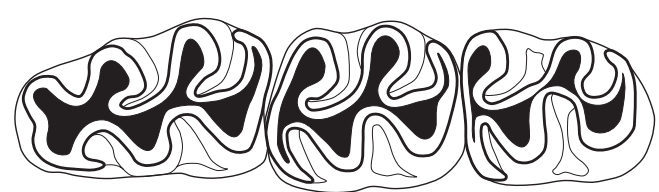

6
Fig. 5.-Yacimiento de Valdocarros: Apodemus sp.: 1: fr. mandíbula izq. con $\mathbf{M}_{1}-\mathbf{M}_{2}$ (Nivel $1 ; 5 ; 17-1$ ); $\mathbf{2}$ : $\mathbf{M}_{3}$ der. (Nivel 1 ; M-5; 71-1); 3: $\mathbf{M}^{1}$ der. (Nivel 3; 10.106; 33-1); 4 : $\mathbf{M}^{2}$ der. (Nivel 2; M-342: 76-1); 5: $\mathbf{M}^{3}$ izq. (Nivel 2; M-342: 76-2); Cricetulus (Allocricetus) bursae SCHAUB, 1930: 6: fr. mandíbula izq. con $\mathbf{M}_{1}-\mathbf{M}_{\mathbf{2}}-\mathbf{M}_{3}$ (Nivel 2: 1-1); 7: $\mathbf{M}^{2}$ der. (Nivel 2: 73-1); 8: $\mathbf{M}^{3}$ der. (Nivel 2: 548; 56-1).

escaso en las fases mas frías llegando a desaparecer de las zonas más septentrionales de Europa durante algunas de las fases de la ultima glaciación wurmiense (Michaux \& Pasquier, 1974; Pemán, 1985; Kowalski, 2001; Sesé, 2005).

\section{Yacimiento: HAT}

Material:

$1 \mathrm{M}_{1}$ izq.; $2 \mathrm{M}_{2}$ der.; $1 \mathrm{M}^{1}$ izq.; $\mathrm{NMI}=2$

Medidas:

\begin{tabular}{lcccccccc}
\hline & & \multicolumn{3}{c}{ Longitud } & & \multicolumn{3}{c}{ Anchura } \\
\cline { 3 - 5 } \cline { 7 - 8 } Diente & $\mathrm{N}$ & Mín. & Med. & Máx. & & Mín. & Med. & Máx. \\
\hline $\mathrm{M}_{1}$ & 1 & - & 1,85 & - & & - & 1,14 & - \\
$\mathrm{M}_{2}$ & 2 & 1,19 & 1,21 & 1,23 & & 1,01 & 1,06 & 1,12 \\
$\mathrm{M}^{1}$ & 1 & - & 1,92 & - & & - & 1,25 & - \\
\hline
\end{tabular}

\section{Descripción y discusión:}

El material de HAT tiene una morfología y una talla similares a las del yacimiento de Valdocarros (ver más arriba) aunque la del $\mathrm{M}^{1}$ es algo mayor, y entra en la variabilidad de la talla de la población de Apodemus cf. sylvaticus de Áridos (López Martínez, 1980 a). Al no haber $\mathrm{M}^{2}$, y por las mismas razones anteriormente indicadas para el yacimiento de Valdocarros, no es posible atribuir el material a ninguna de las dos especies de talla media: Apodemus sylvaticus y Apodemus flavicollis.

Familia Cricetidae FISCHER, 1817 - Cricétidos Subfamilia Cricetinae FISCHER, 1817 - Cricetinos Cricetulus (Allocricetus) bursae SCHAUB, 1930 Hámster migrador

(Fig. 5: 6-8)

Yacimiento: Valdocarros

Material:

\begin{tabular}{|c|c|c|}
\hline Nivel & Material & $\mathrm{NMI}$ \\
\hline 1 & $\begin{array}{l}1 \text { fr. mandíbula der. con } \mathrm{I}, \text { fr. } \mathrm{M}_{1}-\mathrm{M}_{2}-\mathrm{M}_{3} \\
\text { y rama ascendente con cóndilo articular; } \\
1 \text { fr. } \mathrm{M}_{1} \text { izq. }\end{array}$ & 1 \\
\hline 2 & $\begin{array}{l}1 \text { fr. mandíbula izq. con serie dentaria: } \\
\mathrm{M}_{1}-\mathrm{M}_{2}-\mathrm{M}_{3} ; 1 \mathrm{M}_{1} \text { izq.; } 1 \mathrm{M}_{2} \text { izq.; } \\
1 \text { fr. } \mathrm{M}^{1} \text { der.; } 1 \mathrm{M}^{2} \text { der.; } 1 \text { fr. de maxilar } \\
\text { der. con } \mathrm{M}^{3}\end{array}$ & 2 \\
\hline 3 & $\begin{array}{l}1 \text { fr. mandíbula izq. con fr. } M_{1}-M_{2}-\text { fr. } M_{3} \text {; } \\
1 M_{3} \text { izq. }\end{array}$ & 1 \\
\hline Total 1-3 & & 4 \\
\hline
\end{tabular}

Medidas:

\begin{tabular}{|c|c|c|c|c|c|c|c|c|}
\hline \multirow[b]{2}{*}{ Diente } & \multirow[b]{2}{*}{$\mathrm{N}$} & \multicolumn{3}{|c|}{ Longitud } & \multirow[b]{2}{*}{$\mathrm{N}$} & \multicolumn{3}{|c|}{ Anchura } \\
\hline & & Mín. & Med. & Máx. & & Mín. & Med. & Máx. \\
\hline $\mathrm{M}_{1}$ & 2 & 1,90 & 1,96 & 2,02 & 3 & 1,12 & 1,21 & 1,30 \\
\hline $\mathrm{M}_{2}$ & 4 & 1,50 & 1,53 & 1,56 & 4 & 1,25 & 1,33 & 1,40 \\
\hline $\mathrm{M}_{3}$ & 3 & 1,38 & 1,40 & 1,43 & 2 & 1,17 & 1,21 & 1,25 \\
\hline$M^{2}$ & 1 & - & 1,42 & - & 1 & - & 1,24 & - \\
\hline $\mathrm{M}^{3}$ & 1 & - & 1,22 & - & 1 & - & 1,21 & - \\
\hline
\end{tabular}

\section{Descripción y discusión:}

La talla de la población de Valdocarros es mayor que la de la población de Cricetulus (Allocricetus) bursae de Cúllar de Baza I (Ruiz Bustos \& Michaux, 1976), entra dentro de la variabilidad de la de Áridos (López Martínez, 1980 a), aunque el $\mathrm{M}_{1}$ y el $\mathrm{M}^{3}$ son algo más grandes, y asimismo entra dentro de la variabilidad de la talla de las diversas poblaciones de Gran Dolina y Complejo Tres Simas de Atapuerca en las que no hay una variación significativa de la talla que indique ninguna tendencia según Gil (1986 y 1996).

Cricetulus (Allocricetus) bursae se registra en España desde el final del Pleistoceno Inferior en los niveles inferiores de Gran Dolina de Atapuerca (Gil, 1986; Sesé \& Gil, 1987; Sesé, 1994; Sesé \& Sevilla, 1996) y es una especie muy común durante el Pleistoceno Medio y Superior en toda la Península 
Ibérica, excepto en la Cornisa Cantábrica, tal como señala Sesé (2005) y en la región Pirenaica (Arribas, 2004). Se extinguió en el Pleistoceno Superior, siendo su último registro conocido hasta ahora en el yacimiento de Cueva Ambrosio datado entre 17.900 y 16.500 años BP (Sesé \& Soto, 1988; Sesé, 1994; Sesé \& Sevilla, 1996).

Es una especie que para algunos autores es muy similar e incluso la misma que la especie actual Cricetulus migratorius (hámster migrador) del Este de Europa y Asia (Kowalski, 2001) aunque, como dicho autor señala, está por realizar un estudio en profundidad de ambas especies por lo que, dadas las diferencias que muchos autores encuentran entre ambas, mantenemos la denominación de Cricetulus (Allocricetus) bursae para la especie del Pleistoceno.

Según Kowalski (2001) Cricetulus (Allocricetus) bursae fue muy común en toda Europa especialmente durante los periodos más áridos del Pleistoceno.

Cricetulus migratorius vive actualmente en gran variedad de hábitats, desde colinas abruptas y boscosas hasta zonas desérticas o semidesérticas, aunque prefiere las estepas arbustivas, y los lugares pedregosos con vegetación dispersa y las praderas secas (Mitchell- Jones et al., 1999; Marquet, 1993).

\section{Subfamilia Arvicolinae GRAY, 1821 - Arvicolinos Arvicola aff. sapidus MILLER, 1908 - Rata de} agua

(Fig. 6: 1 y Fig. 7: 4)

Yacimiento: Valdocarros

\section{Material:}

- Nivel 2: 1 fr. mandíbula der. con $\mathrm{M}_{1}-\mathrm{M}_{2} ; \mathrm{NMI}=1$

- Nivel sin especificar: 1 fr. mandíbula der. con $\mathrm{M}_{1}$; $\mathrm{NMI}=1$

NMI Total de todos los Niveles $=2$

\section{Medidas:}

$$
1 \mathrm{M}_{1} \text { der.: } \mathrm{L}=3,84 ; \mathrm{A}=1,71
$$

\section{Descripción y discusión:}

Los molares inferiores presentan diferenciado el esmalte, siendo más grueso en la parte posterior de los triángulos como sucede en Arvicola sapidus y a diferencia de Arvicola terrestris en la que es más grueso en la parte anterior de los mismos. Con respecto al material de dicho taxón del yacimiento del Pleistoceno Medio de Áridos (López Martínez, 1980 a), la longitud del ejemplar de Valdocarros entra dentro de la variación de la población de la misma, aunque la anchura es algo mayor que la máxima. El ejemplar de Valdocarros es más pequeño que los valores máximos y medios de la población del yacimiento del Pleistoceno Medio de Cueva del Agua (López Martínez \& Ruiz Bustos, 1977) y es de menor talla que las poblaciones actuales de Arvicola sapidus.

La especie Arvicola sapidus aparece en España avanzado el Pleistoceno Medio en el tercer conjunto de asociaciones de micromamíferos según Sesé \& Sevilla (1996); conjunto que es posterior al segundo conjunto de asociaciones faunísticas del Pleistoceno Medio caracterizadas, según dichas autoras (o.c.), por la presencia de la especie de talla relativamente pequeña Arvicola cantiana HINTON, 1910 (también citada como Arvicola mosbachensis SCHMINDTGEN, 1911 por muchos autores, aunque la anterior denominación es la que tiene prioridad en la sinonimia de ambas especies y también es la más comúnmente utilizada en las últimas décadas), que se registra en el yacimiento de Cúllar de Baza I (Ruiz Bustos \& Michaux, 1976; Sesé, 1989). Clasificada aquélla generalmente como Arvicola cf./aff. sapidus, se registra en los yacimientos del Pleistoceno Medio de Áridos (López Martínez, 1980 a), El Higuerón o Rincón de la Victoria (López Martínez, 1972), Ambrona (Sesé, 1986) y Solana de Zamborino (García García, 1977), entre otros.

Con respecto a este último yacimiento hay una cierta controversia en cuanto a su antigüedad dentro del Pleistoceno Medio. García García (1977) describió Arvicola cf. sapidus en Solana de Zamborino; en efecto, según muestra el propio autor (García García, 1977: Cuadro 15) las medidas de este material son sensiblemente mayores que las de Arvicola cantiana de Cúllar de Baza I (Ruiz Bustos \& Michaux, 1976), e incluso, según nuestras observaciones, es de mayor talla que la de Arvicola aff. sapidus del yacimiento de Áridos (López Martínez, 1980 a). Recientemente Scott \& Gibert (2009), para la fecha numérica relativamente antigua dentro del Pleistoceno Medio que dan para el yacimiento de Solana de Zamborino, se apoyan en la determinación de la especie del género Arvicola como Arvicola cantiana que da Ruiz Bustos (1995) en la lista faunística de dicho yacimiento, especie cuya presencia indicaría, como hemos dicho, cierta antigüedad del yacimiento dentro del Pleistoceno Medio al corresponder al segundo conjunto de asociaciones de micromamíferos de los cuatro conjuntos distinguidos para dicho periodo por Sesé y Sevilla (1996). Sin embargo, remitiéndonos a los datos morfológicos y biométricos de García García (1977) y por todo lo anteriormente expuesto, la determinación correcta de la especie en dicho yacimiento sería, a nuestro juicio, la de Arvicola cf. sapidus, y, por tanto, Solana del Zamborino correspondería al tercer conjunto de asociaciones de micromamíferos según Sesé y Sevilla (1996), es decir, al Pleistoceno Medio avanzado, no inicial.

Arvicola sapidus del sudoeste de Europa es una especie endémica iberoccitana que actualmente sólo se encuentra en toda la Península Ibérica y gran parte de Francia excepto en algunas zonas septentrionales y orientales (Blanco, 1998; Mitchell-Jones et al., 1999; Palomo \& Gisbert, 2002).

Es una especie ripícola que vive preferentemente en las orillas de lagunas, ríos y arroyos de caudales lentos y constantes con abundante vegetación herbácea o de matorral alrededor, ya que es un herbívoro estricto que se alimenta fundamentalmente de juncos (López Martínez, 1980 a; Blanco, 1998; Palomo \& Gisbert, 2002).

Yacimiento: HAT

\section{Material:}

$1 \mathrm{M}_{1}$ der.; 1 fr. $\mathrm{M}_{1}$ der.; $\mathrm{NMI}=2$.

Además de estos dientes hay 1 molar y 5 fragmentos de molares que no corresponden al primer molar inferior y que pertenecen al género Arvicola.

\section{Medidas:}

$$
1 \mathrm{M}_{1} \text { der.: } \mathrm{L}=3,64 ; \mathrm{A}=1,64
$$

\section{Descripción y discusión:}

Estos ejemplares son de morfología y talla similares al material de Valdocarros. La longitud entra dentro de la variabilidad 

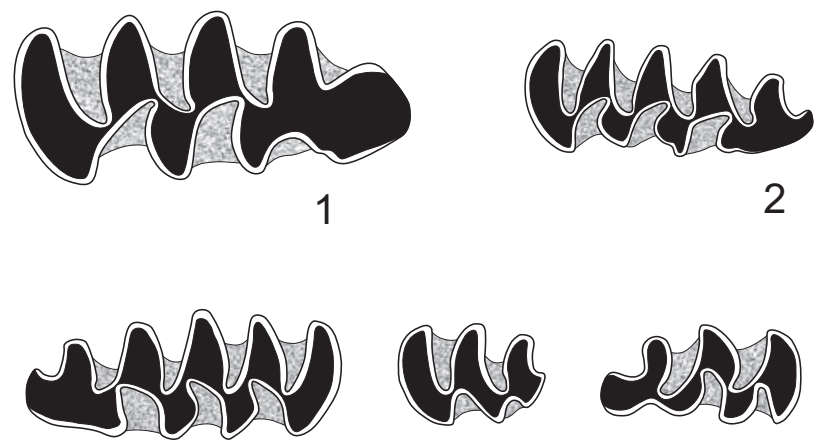

3

4

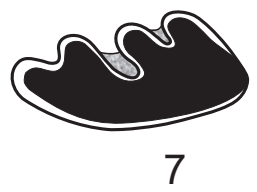

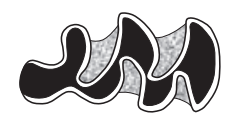

5
6

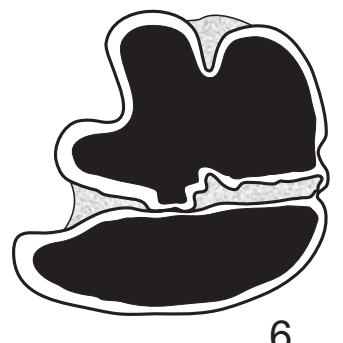

(1)

\section{$1 \mathrm{~mm}$}

Fig. 6.-Yacimiento de Valdocarros: Arvicola aff. sapidus MILLER, 1908: 1: $\mathbf{M}_{1}$ der. (Nivel 2; 12.227; 39-1); Microtus brecciensis (GIEBEL, 1847): $\mathbf{2}: \mathbf{M}_{1}$ der. (Nivel 2; 122; 18-1); $\mathbf{3}$ : $\mathbf{M}_{1}$ izq. (Nivel $\left.1 ; 10.009 ; 27-8\right) ; 4: \mathbf{M}_{3}$ der. (Nivel 1; 10.009; $27-$ 14); 5: $\mathbf{M}^{3}$ izq. (Nivel 2; 10.008; 28-1); Oryctolagus cuniculus (LINNAEUS, 1758): 6: $\mathbf{P}_{3}$ izq. (Nivel 2; 301; 13-2); 7 : $\mathbf{P}^{2}$ izq. (Nivel 3; 63-1).

de la de la población de Áridos según López Martínez (1980a); sin embargo la anchura es mayor que la máxima de esta última. La talla del material de HAT es más pequeña que las poblaciones actuales de Arvicola sapidus.

Microtus brecciensis (GIEBEL, 1847) - Topillo de la brechas

(Fig. 6: 2-5)

\section{Yacimiento: Valdocarros}

Material:

Hay 3 fragmentos de mandíbulas con $\mathrm{M}_{1}-\mathrm{M}_{2}$; los demás molares se encuentran aislados. Además de la relación de $\mathbf{M}_{1}$, que se da a continuación, hay $5 \mathrm{M}_{3}, 8 \mathrm{M}^{3}$ y otros 16 molares aislados no atribuibles a ninguno de estos.

\begin{tabular}{lcccc}
\hline Nivel & $\mathrm{N}^{\circ} \mathrm{M}_{1}$ der. & $\mathrm{N}^{\circ} \mathrm{M}_{1}$ izq. & $\mathrm{N}^{\mathrm{o}}$ Total $\mathrm{M}_{1}$ & $\mathrm{NMI}$ \\
\hline 1 & 2 & 3 & 5 & 3 \\
2 & 6 & 4 & 10 & 6 \\
3 & 8 & 4 & 12 & 8 \\
N.s.e. & 1 & - & 1 & 1 \\
Total & 17 & 11 & 28 & 18 \\
\hline
\end{tabular}

Nota: N.s.e. $=$ Nivel sin especificar

Medidas:

\begin{tabular}{|c|c|c|c|c|c|c|c|c|}
\hline \multirow[b]{2}{*}{ Diente } & \multirow[b]{2}{*}{$\mathrm{N}$} & \multicolumn{3}{|c|}{ Longitud } & \multirow[b]{2}{*}{$\mathrm{N}$} & \multicolumn{3}{|c|}{ Anchura } \\
\hline & & Mín. & Med. & Máx. & & Mín. & Med. & Máx. \\
\hline $\mathrm{M}_{1}$ & 17 & 2,67 & 2,88 & 3,17 & 16 & 1,07 & 1,20 & 1,32 \\
\hline $\mathrm{M}_{3}$ & 4 & 1,25 & 1,42 & 1,52 & 4 & 0,94 & 1,01 & 1,13 \\
\hline $\mathrm{M}^{3}$ & 7 & 1,76 & 1,87 & 2,0 & 7 & 0,84 & 0,97 & 1,01 \\
\hline
\end{tabular}

\section{Descripción y discusión:}

En el $\mathrm{M}_{1}$ de Microtus brecciensis de Valdocarros, los morfotipos del complejo anterocónido más abundantes y prácticamente constantes en toda la población (ver Fig. 6: 2 y 3) son los morfotipos 6 y 7 (según López Martínez, 1980 a), que son también los más frecuentes respectivamente por orden decreciente en la población de dicha especie del yacimiento del Pleistoceno Medio de Áridos (o.c.). En el $\mathrm{M}_{1}$ de Valdocarros, la longitud entra dentro de la variabilidad de la población de Microtus brecciensis de Áridos (López Martínez, 1980 a), situándose en el intervalo comprendido aproximadamente entre los valores medios y máximos de esta última, mientras que la anchura alcanza valores mayores en aquélla. La talla del $\mathrm{M}_{1}$ de Valdocarros entra dentro de la variabilidad de la de la población de Microtus brecciensis del yacimiento del Pleistoceno Medio de Cúllar de Baza I (Ruiz Bustos \& Michaux, 1976).

Todos los $\mathrm{M}_{3}$ de Valdocarros presentan el morfotipo 3 (T1 y T2 confluyentes) (Fig. 6: 4) según Ayarzagüena \& López Martínez (1976), característico de Microtus brecciensis, que también es el más abundante y se da en más de la mitad de la población de Áridos (López Martínez, 1980 a). El M 3 de Valdocarros alcanza tallas mayores que las de el de Áridos y la variabilidad de la talla del $\mathbf{M}^{3}$ se sitúa entre la media y la máxima de la de dicho yacimiento según López Martínez (1980 a). Con respecto a los 3 morfotipos de la variabilidad de la cúspide posterior del $\mathrm{M}^{3}$ que se dan en la población de Áridos según López Martínez (1980 a), los $\mathrm{M}^{3}$ de Valdocarros se reparten en: 3 ejemplares del morfotipo 1, otros 3 del morfotipo 2 (Fig. 6: 5) y uno del morfotipo 3.

Las longitudes de los dos $\mathrm{M}_{1}$ de Microtus brecciensis del yacimiento del Pleistoceno Medio de Ambrona (Sesé, 1986; Sesé \& Soto, 2005), caen dentro de la variación de la talla de la población de Valdocarros, próximas al valor mínimo de ésta.

Con respecto a la población de Microtus brecciensis de Huéscar 1 (Mazo et al., 1985), yacimiento de una edad del tránsito del Pleistoceno Inferior al Pleistoceno Medio según Sesé y Sevilla (1996), el $M_{1}$ de Valdocarros tiene una talla mayor y una morfología más avanzada.

Comparado con las poblaciones de Microtus brecciensis de Atapuerca descritas por Sesé y Gil (1987) (solo las de los niveles inferiores de Gran Dolina) y por Gil (1986 y 1997) (las de Gran Dolina y Complejo Tres Simas), la talla del $\mathbf{M}_{1}$ de Valdocarros: es más grande que las de los niveles inferiores de Gran Dolina TD3, TD4, TD5 y TD6, algo mayor también que la de TD8, y menor que la del único ejemplar del nivel superior de Gran Dolina (TD11); entra dentro de la variabilidad de la de los niveles TN4 y TN6 de Tres Simas-Conducto Vertical; mientras que la talla de las poblaciones de Galería (TG9, TG10 y TG11), aunque con escasos ejemplares, son próximas a los valores máximos de Valdocarros. En cuanto a la morfología, el com- 
plejo anterocónido del $\mathrm{M}_{1}$ de estas últimas poblaciones de Atapuerca (TD11, TN4, TG9, TG10 y TG11) está más evolucionado que la de la población de Valdocarros por el mayor desarro1lo del T6 y del entrante LRA5 (Gil, 1997: Fig. 1, p. 114). Cuenca-Bescós et al. (1995), cambian la determinación de la especie Microtus brecciensis de los niveles inferiores TD3 y TD4 de Gran Dolina por la de Iberomys sp. y posteriormente Laplana y Cuenca Bescós (1998) por la de Microtus (Iberomys) huescarensis RUIZ BUSTOS, 1988, cuyo registro amplían hasta el nivel TD8 de Gran Dolina. Según Laplana y Cuenca Bescós (1998) esta última especie sería la antecesora de Microtus brecciensis, y característica del final del Pleistoceno Inferior y la base del Pleistoceno Medio. Al igual que se ha dicho más arriba, el $\mathrm{M}_{1}$ de Valdocarros es de talla mayor y de morfología más evolucionada que las de los mencionados niveles inferiores de Gran Dolina descritas por Cuenca-Bescós et al. (1995) y Laplana y Cuenca Bescós (1998).

Con respecto a la población de Microtus brecciensis del yacimiento del Pleistoceno Medio de Cueva del Agua (López Martínez \& Ruiz Bustos, 1977), la talla de la población de Valdocarros es más pequeña. En cuanto a la morfología del $\mathrm{M}_{3}$, así como en Valdocarros solo se encuentra el morfotipo 3 de Ayarzagüena \& López Martínez (1976) y López Martínez (1980 a), en Cueva del Agua (López Martínez \& Ruiz Bustos, 1977) la población se reparte entre los 3 morfotipos, aunque es también el morfotipo 3 el más abundante, lo que indica que esta última población está más evolucionada.

La talla de la población de Valdocarros es más pequeña que la de Pinilla del Valle (Toni \& Molero, 1990). En este yacimiento, la determinación de Microtus brecciensis realizada por Toni y Molero (1990), ha pasado recientemente a ser Microtus cabrerae porque presenta los caracteres progresivos típicos de esta especie y corresponde, por tanto, al Pleistoceno Superior según Laplana \& Sevilla (2006).

Microtus brecciensis es el segundo taxón más abundante por orden decreciente en Valdocarros constituyendo el $31 \%$ del NMI total del yacimiento (véase Cuadro1). Igualmente, en el yacimiento de Áridos (López Martínez, 1980 a) esta especie es la segunda más abundante y en un porcentaje del NMI muy similar (29\%).

Microtus brecciensis es una especie típica del Pleistoceno Medio en la Península Ibérica, muy común en prácticamente todos los yacimientos de esta edad (Ayarzagüena \& López Martínez, 1976; Sesé, 1994; Sesé \& Sevilla, 1996). Es un endemismo iberoccitano ya que durante el Pleistoceno Medio solo se registra, además de en España, en la Francia mediterránea (Marquet, 1993) y extremo noroccidental mediterráneo de Italia (Ayarzagüiena \& López Martínez, 1976).

Por lo que respecta al tipo de hábitat de esta especie, remitimos al siguiente apartado de Microtus cabrerae.

\section{Microtus cf. cabrerae THOMAS, 1906 - Topillo de Cabrera}

(Fig. 7: 5)

\section{Yacimiento: HAT}

\section{Material:}

$1 \mathrm{M}_{1}$ izq.; 1 fr. $\mathrm{M}_{1}$ izq.; $2 \mathrm{M}^{3}$ izq.; $\mathrm{NMI}=2$.

Además de estos dientes hay 11 molares y 16 fragmentos de molares atribuibles al género Microtus que no corresponden ni al $\mathrm{M}_{1}$ ni al $\mathrm{M}^{3}$.

\section{Medidas:}

$$
1 \mathrm{M}_{1}: \mathrm{L}=(3,21) ; \mathrm{A}=(1,38)
$$

Descripción y discusión:

El $\mathrm{M}_{1}$ es de mayor talla que las poblaciones de Microtus brecciensis de los yacimientos de Valdocarros (ver medidas más arriba) y Áridos (López Martínez, 1980 a), sobrepasando los valores máximos de ambas; sin embargo entra en la variabilidad de la de Microtus cabrerae actual según los datos de Ayarzagüena \& López Martínez (1976) y López Martínez (1980 a), aunque próxima a los valores mínimos de ésta por lo que respecta a la longitud. Aunque los ejemplares de HAT están muy erosionados, comparándolos con ejemplares actuales de esta última especie muestran una morfología similar, con el desarrollo de un triángulo T6 incipiente en los dos ejemplares. El escaso material y su mal estado de conservación no permiten sin embargo realizar con seguridad su identificación específica, razón por la que lo determinamos como Microtus cf. cabrerae.

Microtus cabrerae es la especie actual que durante el Pleistoceno Superior sucede por evolución a Microtus brecciensis del Pleistoceno Medio. Ayarzagüena \& López Martínez (1976) y Cabrera-Millet et al. (1982) comparan morfo-biométricamente ambas especies señalando los caracteres distintivos de ambas, principalmente el aumento de talla y los cambios en la morfología de algunos de los molares, especialmente del $\mathrm{M}_{1}$ y del $\mathrm{M}_{3}$.

Microtus cabrerae, que se encuentra en el Pleistoceno Superior y Holoceno en numerosos yacimientos de la Península Ibérica (Arribas, 2004; López García, 2008) y la Francia mediterránea, en la actualidad es una especie relicta ibérica ya que se ha restringido su distribución geográfica a la Península Ibérica (Ayarzagüena \& López Martínez, 1976; Cabrera-Millet et al., 1982). Ninguna de las dos especies se registra, sin embargo, en la Cornisa Cantábrica; tal como señaló Sesé (2005), es muy notable la ausencia de Microtus cabrerae en los numerosos yacimientos del Pleistoceno Superior de dicha región (Altuna, 1972; Ayarzagüena \& López Martínez, 1976; Pokines, 1998; Sesé, 2005).

El área de distribución actual de Microtus cabrerae en la Península Ibérica está fragmentada; se encuentra en las estribaciones meridionales y occidentales de los principales sistemas montañosos de las zonas mediterráneas de la Península Ibérica: Pre-Pirineo, Sistema Ibérico meridional, Sistema Central, Sierras Béticas, algunas zonas de Zamora y algunas áreas de la mitad sur de Portugal. En la Comunidad de Madrid se encuentra en el extremo más sureste lindando con la provincia de Cuenca, y, de forma casi continua, más o menos desde el centro hasta prácticamente toda la región occidental menos la zona más septentrional de la comunidad (Blanco, 1998; Palomo \& Gisbert, 2002; Palomo et al., 2007).

La especie Microtus cabrerae está ligada actualmente a suelos muy húmedos, bien en las proximidades de manantiales o en zonas en las que el nivel freático aflora en superficie formando charcas estacionales, en las que hay siempre abundante vegetación que se mantiene verde todo el año compuesta principalmente de juncales, gramíneas y en menor medida de carrizales. Se trata de un herbívoro estricto muy especializado en su alimentación basada, sobre todo, en Juncus, Scirpus y TrifolionCynodontion (Ayarzagüena et al., 1976; Ayarzagüena \& López Martínez, 1976; López Martínez, 1980 a; Castells \& Mayo, 1993; Blanco, 1998; Palomo \& Gisbert, 2002). Es una especie mediterránea que evita el clima eurosiberiano (Blanco, 1998; Palomo \& Gisbert, 2002), como pone de manifiesto su distribu- 
ción geográfica tanto en el Cuaternario como la actual, aunque también evita las regiones con temperaturas veraniegas elevadas (Mitchell-Jones et al., 1999).

En cuanto a la paleoecología de su antecesor del Pleistoceno Medio, Microtus brecciensis (presente en el yacimiento de Valdocarros como se ha indicado antes), Cabrera-Millet et al. (1982) indican que no deben trasponerse directamente a esta especie los hábitats de Microtus cabrerae ya que, los cambios morfológicos y biométricos que experimentan en el paso de una a otra, podrían reflejar el cambio de una especie poco especializada y euritópica a una especie más especializada y estenotópica, por lo que el nicho ecológico de Microtus brecciensis podría ser más amplio. Podemos suponer, de todas formas, que Microtus brecciensis era una especie propia de un clima templado por su distribución en el área mediterránea durante el Pleistoceno Medio y que, por su similitud con la especie actual Microtus cabrerae, que es su descendiente, podría estar ligada igualmente a suelos húmedos con abundante vegetación, aunque no necesariamente tenía que estar tan especializado en su alimentación.

Orden Lagomorpha BRANDT, 1855 - Lagomorfos Familia Leporidae FISCHER, 1817 - Lepóridos Oryctolagus cuniculus (LINNAEUS, 1758) Conejo

(Fig. 6: 6-7)

\section{Yacimiento: Valdocarros}

Material:

- Nivel 0: 1 fr. mandíbula der. con $\mathrm{P}_{3}-\mathrm{P}_{4} ; 1 \mathrm{P} / \mathrm{M}$ inf.; 3 fr. P/M inf.; 2 I inf.; 2 P/M sup.; NMI = 1

- Nivel 1: $1 \mathrm{D}_{3}$ der.; $1 \mathrm{D}_{3}$ izq.; 1 fr. mandíbula der. con I$\mathrm{P}_{3}-\mathrm{P}_{4}-\mathrm{M}_{1}$; 3 P/M inf.; 6 fr. P/M inf.; $1 \mathrm{M}_{3}$; 2 I inf.; $3 \mathrm{P}^{2}$ der.; 1 $\mathrm{P}^{2}$ izq.; $9 \mathrm{P} / \mathrm{M}$ sup.; 5 fr. $\mathrm{P} / \mathrm{M}$ sup.; 2 fr. maxilar con impronta de alveolos de $\mathrm{P} / \mathrm{M}$ der. e izq.; $\mathrm{NMI}=3$

- Nivel 2: 2 fr. mandíbulas izq. con $\mathrm{P}_{3}-\mathrm{P}_{4}-\mathrm{M}_{1}-\mathrm{M}_{2} ; 5 \mathrm{P}_{3}$ der.; $6 \mathrm{P}_{3}$ izq.; 2 fr. $\mathrm{P}_{3}$ izq.; $5 \mathrm{M}_{3}$; $31 \mathrm{P} / \mathrm{M}$ inf.; 25 fr. $\mathrm{P} / \mathrm{M}$ inf.; $13 \mathrm{I}$ inf.; 2 fr. I inf.; 2 fr. mandíbulas der. con alveolos de premolares y molares; 2 fr. mandíbulas izq. con alveolos de premolares y molares; 2 fr. mandíbulas con alveolo del tercer premolar; $1 \mathrm{P}^{2}$ izq.; 15 P/M sup.; 9 fr. P/M sup.; 7 I sup.; 5 fr. I sup.; NMI = 10

- Nivel 3: $3 \mathrm{P}_{3}$ der.; 1 fr. $\mathrm{P}_{3}$ der.; $4 \mathrm{P}_{3}$ izq.; 1 fr. mandíbula con $\mathrm{M}_{2}-\mathrm{M}_{3}$; 1 fr. mandíbula con $3 \mathrm{P} / \mathrm{M} ; 9 \mathrm{P} / \mathrm{M}$ inf.; 16 fr. P/M inf.; 2 M3 inf.; 5 I inf.; 5 fr. I inf.; 2 fr. mandíbulas; 1 fr. maxilar der. con: $\mathrm{P}^{2}-\mathrm{P}^{3}-\mathrm{P}^{4}$, alveolos de los molares y parte del arco zigomático; $1 \mathrm{P}^{2}$ der.; 1 fr. $\mathrm{P}^{2}$ der.; $2 \mathrm{P}^{2}$ izq.; 2 fr. $\mathrm{P}^{2}$ izq.; 18 P/M sup.; 13 fr. P/M sup.; 4 I sup.; 4 fr. I sup.; 1 fr. D; NMI = 4 - Nivel 4: $1 \mathrm{P}_{3}$ der.; $1 \mathrm{P} / \mathrm{M}$ inf.; 2 fr. P/M inf.; $1 \mathrm{I}$ inf.; 1 $\mathrm{P} / \mathrm{M}$ sup.; 3 fr. I sup.; $\mathrm{NMI}=1$

- Nivel sin especificar: 1 fr. mandíbula der. con fr. $\mathrm{P}_{3^{-}}$fr. $\mathrm{P}_{4^{-}}$fr. $\mathrm{M}_{1}$ y alveolo del segundo molar; $1 \mathrm{P}_{3}$ der.; $1 \mathrm{P}_{3}$ izq.; 4 P/M inf.; 1 fr. P/M inf.; 1 fr. mandíbula der. con $\mathrm{M}_{3} ; 1 \mathrm{M}_{3} ; 1 \mathrm{I}$ inf.; 4 fr. I inf.; NMI = 2

NMI Total de todos los Niveles $=21$

Muchos de los dientes, cuya relación se da aquí como piezas aisladas, originalmente debían encontrarse en el yacimiento insertos en sus correspondientes mandíbulas y maxilares ya que están asociados en la misma muestra (misma cuadrícula, nivel, etc.) y encajan perfectamente, por lo que pudieron desprenderse, bien durante la excavación, el lavado de sedimento o en su posterior manipulación. En algunos casos, en la misma muestra se registra material que podría pertenecer muy probablemente a la mandíbula izquierda y derecha de un mismo individuo. Lo mismo se puede decir de algunos dientes y sus respectivos maxilares. Es decir, que entre estos restos, hay bastante material dentario que se puede hacer corresponder casi con seguridad con el individuo al que pertenecían.

\section{Medidas:}

\begin{tabular}{|c|c|c|c|c|c|c|c|c|}
\hline \multirow[b]{2}{*}{ Diente } & \multirow[b]{2}{*}{$\mathrm{N}$} & \multicolumn{3}{|c|}{ Longitud } & \multirow[b]{2}{*}{$\mathrm{N}$} & \multicolumn{3}{|c|}{ Anchura } \\
\hline & & Mín. & Med. & Máx. & & Mín. & Med. & Máx. \\
\hline $\mathrm{P}_{3}$ & 20 & 1,88 & 2,76 & 3,12 & 20 & 1,99 & 2,83 & 3,53 \\
\hline $\mathrm{P}^{2}$ & 8 & 1,18 & 1,46 & 1,61 & 9 & 2,40 & 2,96 & 3,29 \\
\hline
\end{tabular}

\section{Descripción y discusión:}

En el Pleistoceno Medio hay dos especies del género Oryctolagus: Oryctolagus lacosti, que se registra en Europa en el Plioceno y Pleistoceno, y en España durante el Pleistoceno Inferior y Medio, y Oryctolagus cuniculus, cuyo primer registro en España hasta ahora es en el yacimiento del Pleistoceno Medio de Cúllar de Baza I (López Martínez, 1989). Algunas de las características de la especie Oryctolagus lacosti según López Martínez (1989) son: que los dientes, la serie dentaria y el hueso mandibular son más robustos que en Oryctolagus cuniculus y similares a los del género Lepus, y que presenta caracteres intermedios entre conejo y liebre. En una comparación del material de Valdocarros con poblaciones actuales de Oryctolagus cuniculus presenta una total identidad tanto en la morfología como en la talla con esta especie. $\mathrm{El}_{3}$ tiene anterocónidos subiguales, anterofléxido ancho y ortogonal e hipofléxido simple; el $\mathrm{P}^{2}$ tiene postcono y metaflexo bien diferenciados, todos ellos caracteres propios de dicha especie según López Martínez (1989).

El conejo es sin duda el taxón de micromamíferos más abundante y mejor representado en el yacimiento de Valdocarros constituyendo el 36\% del NMI total del yacimiento (véase Cuadro 1). No obstante, hay que hacer algunas precisiones respecto a su abundancia relativa ya que podría estar sobre representado en el yacimiento, con respecto a otros taxones, debido a los siguientes factores: 1) Es un material que por su tamaño relativamente grande, en relación a otros taxones de micromamíferos, se ve a simple vista, y por tanto es fácilmente recuperable durante la propia excavación y también en el lavado de sedimento utilizando cribas con luces de malla de más de $1 \mathrm{~mm}$; 2 ) Los lagomorfos en general tienen más dientes que otros taxones de micromamíferos, como por ejemplo los roedores, y además todos ellos son fácilmente reconocibles, incluso los incisivos. Aún teniendo en cuenta estos factores, hay que señalar que quedan en gran parte corregidos al utilizar, en la comparación de la abundancia relativa de los distintos taxones de micromamíferos del yacimiento, el NMI de la pieza más característica taxonómicamente, el $\mathrm{P}_{3}$, y en ausencia de ésta, el $\mathrm{P}^{2}$, y no el NR (número de restos). Por otra parte, en una comparación con lo que sucede en este sentido en el yacimiento de Áridos (López Martínez, 1980 a), igualmente es el conejo (aunque una especie diferente: Oryctolagus cf. lacosti) el micromamífero más abundante y casi con el mismo porcentaje del NMI (35\%).

Oryctolagus cuniculus es una especie muy común en los yacimientos de España del Pleistoceno Medio y Superior (Sesé, 


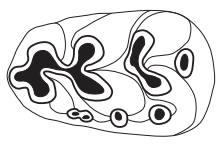

1

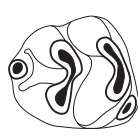

2

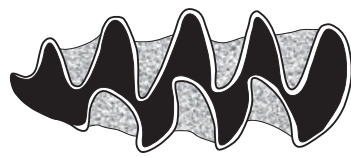

5

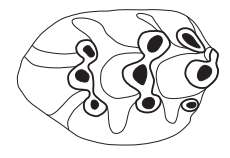

3

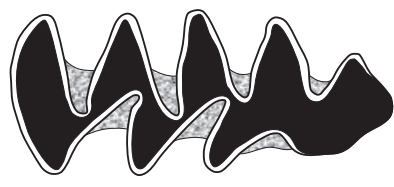

4

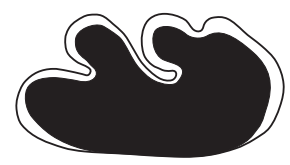

6
Fig. 7.-Yacimiento de HAT: Apodemus sp.: 1: $\mathbf{M}_{1}$ izq. (9-1); 2: $\mathbf{M}_{\mathbf{2}}$ der. (5-1); 3: $\mathbf{M}^{\mathbf{1}}$ izq. (7-1); Arvicola aff. sapidus MILLER, 1908: 4: $\mathbf{M}_{1}$ der.(1-1); Microtus cf. cabrerae THOMAS, 1906: 5: $M_{1}$ izq. (1-2); cf. Oryctolagus sp.: 6: $P^{2}$ izq. (2-1).

1994). Sin embargo esta especie es poco frecuente y, cuando aparece, es poco abundante en los yacimientos pleistocenos y holocenos de la Región Cantábrica (Altuna, 1972; Aguirre, 1989; Sesé, 2005). Es una especie originaria de España que parece que se expandió al resto del continente europeo en tiempos históricos (López Martínez, 1989; Blanco, 1998; MitchellJones et al., 1999).

Actualmente se encuentra en toda España pero parece menos frecuente en la España eurosiberiana: Galicia, Cornisa Cantábrica (faltando prácticamente de Asturias) y región pirenaica, y en las zonas frías de alta montaña, mientras que las densidades más altas se dan en la zona suroccidental de clima mediterráneo. Su hábitat ideal son las dehesas con abundante matorral mediterráneo y pastizales, clima continental o mediterráneo con veranos secos y calurosos y precipitaciones en torno a los 500 $\mathrm{mm}$, siendo las bajas temperaturas y las precipitaciones elevadas los factores limitantes de sus distribución (Blanco, 1998; Palomo \& Gisbert, 2002).

\section{cf. Oryctolagus sp. - Conejo}

(Fig. 7: 6)

\section{Yacimiento: $H A T$}

Material:

1 I inf.; 2 P/M inf.; 1 fr. P/M inf.; 1 fr. I sup.; $1 \mathrm{D}^{2}$ der.; $1 \mathrm{P}^{2}$ izq.; $1 \mathrm{P} / \mathrm{M}$ sup.; $\mathrm{NMI}=2$

\section{Medidas:}

$$
1 \mathrm{P}^{2}: \mathrm{L}=(1,43) ; \mathrm{A}=2,59
$$

\section{Descripción y discusión:}

En el $\mathrm{P}^{2}$ los tres flexos están presentes, de los cuales el más profundo es el paraflexo, estando el hipoflexo bien desarrollado, como sucede en el género Oryctolagus a diferencia del género Lepus en el que este último es muy corto según López Martínez (1989). Por otra parte, el material de HAT es de talla y morfología similares al del Valdocarros. Sin embargo, dada la escasez de material y la ausencia de piezas dentarias que presenten caracteres con valor diagnóstico como el $\mathrm{P}_{3}$, no se puede precisar con más seguridad su determinación taxonómica.

\section{Discusión y conclusiones}

\section{Valdocarros}

La asociación faunística de micromamíferos determinada en este trabajo en el yacimiento de Valdocarros es la siguiente:

Orden Erinaceomorpha GREGORY, 1910

Familia Erinaceidae FISCHER, 1814 Erinaceus europaeus LINNAEUS, 1758

Orden Soricomorpha GREGORY, 1910

Familia Soricidae FISCHER, 1814 Crocidura aff. russula (HERMANN, 1780)

Orden Rodentia BOWDICH, 1821

Familia Gliridae MUIRHEAD, 1819

Eliomys quercinus (LINNAEUS, 1766)

Familia Castoridae HEMPRICH, 1820

Castor fiber LINNAEUS, 1758

Familia Muridae ILLIGER, 1811 Apodemus sp.

Familia Cricetidae FISCHER, 1817 Cricetulus (Allocricetus) bursae SCHAUB, 1930 Arvicola aff. sapidus MILLER, 1908

Microtus brecciensis (GIEBEL, 1847)

Orden Lagomorpha BRANDT, 1855

Familia Leporidae FISCHER, 1817 Oryctolagus cuniculus (LINNAEUS, 1758)

La asociación de micromamíferos del yacimiento de Valdocarros es propia del Pleistoceno Medio. De las mencionadas especies, Microtus brecciensis es una de las más características de este periodo. Por la talla y la morfología, la población de esta especie de Valdocarros está más evolucionada que las del yacimiento de Huéscar 1 y las de los niveles inferiores de Gran Dolina de Atapuerca, todas ellas de una edad del final del Pleistoceno Inferior o tránsito del Pleistoceno Inferior al Pleistoceno Medio (atribuidas las poblaciones de este último yacimiento por Sesé y Gil, 1987 y Gil, 1986 y 1997 a Microtus brecciensis, y por Laplana y Cuenca Bescós, 
Tabla 1.-Distribución y abundancia de los taxones de micromamíferos del yacimiento de Valdocarros por niveles y total según el NMI y el porcentaje del NMI. Nota: N.s.e. = Nivel sin especificar

\begin{tabular}{|c|c|c|c|c|c|c|c|c|}
\hline Niveles & Nivel 0 & Nivel 1 & Nivel 2 & Nivel 3 & Nivel 4 & N.s.e. & Total & Total \\
\hline Taxones & NMI & NMI & NMI & NMI & NMI & NMI & NMI & $\% \mathrm{NMI}$ \\
\hline Erinaceus europaeus & & & & 2 & & & 2 & 3 \\
\hline Crocidura aff. russula & & 1 & & 1 & 1 & & 3 & 5 \\
\hline Eliomys quercinus & & & 1 & & & & 1 & 2 \\
\hline Castor fiber & & & 2 & & & & 2 & 3 \\
\hline Apodemus sp. & & 3 & 2 & 1 & & & 6 & 10 \\
\hline Cricetulus (Allocricetus) bursae & & 1 & 2 & 1 & & & 4 & 7 \\
\hline Arvicola aff. sapidus & & & 1 & & & 1 & 2 & 3 \\
\hline Microtus brecciensis & & 3 & 6 & 8 & & 1 & 18 & 31 \\
\hline Oryctolagus cuniculus & 1 & 3 & 10 & 4 & 1 & 2 & 21 & 36 \\
\hline Total & 1 & 11 & 24 & 17 & 2 & 4 & 59 & 100 \\
\hline
\end{tabular}

1998 a Microtus (Iberomys) huescarensis, que consideran la especie antecesora de Microtus brecciensis); es próxima, aunque está algo más evolucionada, que la de Microtus brecciensis del yacimiento del Pleistoceno Medio de Áridos; y menos evolucionada que la de los yacimientos del Pleistoceno Medio de Cueva del Agua y algunos de los niveles superiores de Gran Dolina, Galería y Tres SimasConducto Vertical de Atapuerca.

El material de Arvicola aff. sapidus es de talla próxima al del yacimiento de Áridos y algo menor que el de Cueva del Agua y las poblaciones actuales de la especie.

Por todo ello, creemos que esta asociación se situaría en el tercer conjunto de asociaciones de micromamíferos del Pleistoceno Medio según Sesé \& Sevilla (1996) y que corresponde, por lo tanto, al Pleistoceno Medio avanzado, pero no final. Este tercer conjunto, en el que se incluyen las faunas de Áridos, El Higuerón, Solana de Zamborino y Ambrona, entre otros, está caracterizado por una forma del género Arvicola denominada Arvicola aff. sapidus por su menor talla con respecto a las poblaciones actuales de dicha especie. El tercer conjunto es posterior al segundo conjunto de asociaciones de micromamíferos del Pleistoceno Medio (en el que se sitúa la asociación de Cúllar de Baza I), que está caracterizado por la especie de pequeña talla del género Arvicola: Arvicola cantia$n a$, y es anterior al cuarto conjunto del final del Pleistoceno Medio, que presenta mayor diversidad de arvicólidos (Pliomys lenki y varias especies del género Microtus), como sucede en Cueva del Agua y los niveles superiores de Gran Dolina y Complejo
Tres Simas de Atapuerca (Sesé \& Sevilla, 1996). Dentro del tercer conjunto de asociaciones de micromamíferos del Pleistoceno Medio, la asociación de Valdocarros II (situada en Arganda II) sería biostratigráficamente algo posterior a la de Áridos I (situada en Arganda I).

De todos los taxones identificados en Valdocarros, actualmente Erinaceus europaeus, Crocidura russula, Eliomys quercinus, el género Apodemus, Arvicola sapidus y Oryctolagus cuniculus viven en la región. Microtus brecciensis está representado en la actualidad por su descendiente Microtus cabrerae en la zona o no muy lejos. Cricetulus (Allocricetus) bursae tuvo su último registro conocido hasta ahora en España casi al final del Pleistoceno Superior y está representado actualmente por una especie muy próxima, Cricetulus migratorius, en el este de Europa y Asia. Finalmente Castor fiber se extinguió en España en tiempos históricos persistiendo hasta la actualidad en algunos enclaves aislados europeos.

Todos estos micromamíferos podrían haber vivido en la zona del yacimiento o en sus proximidades.

La gran mayoría de los fósiles recuperados están muy bien conservados, aunque hay unos pocos huesos y dientes que muestran una erosión que podría haberse ocasionado por rodamiento, por haber estado expuestos a las condiciones meteorológicas durante un tiempo, o por procesos posdeposicionales. Sin embargo, por lo general, no parece haber demasiada dispersión ni señales de rodamiento en el material fósil craneal. En este sentido, se encuentran en muchas de las muestras recogidas en áreas muy reducidas, partes craneales (maxilares y man- 
díbulas de ambos lados con la dentición correspondiente) pertenecientes a un mismo taxón (de algunos erinaceomorfos y roedores, pero sobre todo de lagomorfos, como ya se dijo en sus apartados correspondientes) que podrían probablemente pertenecer a un mismo individuo. Sin embargo, durante la excavación no se han observado piezas esqueléticas postcraneales de micromamíferos en conexión anatómica, excepto alguna extremidad de conejo. La buena conservación, por lo general, del material craneal, junto con el hecho de que se encuentren asociadas muchas mandíbulas y maxilares con su dentición, permiten suponer que la mayoría o gran parte de los restos parecen haber sido enterrados con cierta rapidez y con poco o nulo transporte, en todo caso no muy lejos de su lugar de depósito inicial. Por otra parte, hay también algunos dientes que muestran el desgaste típico (especialmente observable en los arvicólidos) producido posiblemente por la acción de jugos gástricos de predadores, probablemente de aves rapaces.

Tanto la composición faunística de este yacimiento, como la representación porcentual de las especies dominantes (el conejo con el 36\% de los restos y Microtus brecciensis con el 31\%) es similar a la del yacimiento de Áridos, cuyos valores respectivamente son $35 \%$ y $27 \%$ (obtenidos a partir de los datos del NMI de López Martínez, 1980 a), aunque en este último yacimiento el conejo está representado por una especie diferente: Oryctolagus cf. lacosti. En este sentido, es muy notable en este tipo de yacimientos la gran abundancia de conejo, ya que los lagomorfos, cuando aparecen en egagrópilas actuales, no suelen ser ni muy abundantes ni los elementos predominantes (Andrews, 1990; Chaline et al., 1974). A este respecto, en el yacimiento de Áridos, próximo tanto geográfica como biostratigráficamente al de Valdocarros, del estudio tafonómico de la asociación faunística de vertebrados, López Martínez (1980 b) concluye que la acumulación de restos es el resultado de la predación humana. Sin embargo en el yacimiento de Valdocarros no tenemos argumentos actualmente para documentar o descartar la acción humana sobre parte de los micromamíferos.

Desde un punto de vista paleoecológico, prácticamente todas las especies de Valdocarros precisan actualmente para vivir bastante cobertura vegetal, bien sea de bosque, sotobosque, arbustiva o herbácea. Incluso por lo que respecta a la única especie esteparia de la asociación, el hámster migrador (Cricetulus (Allocricetus) bursae), que constituye el
$7 \%$ del total de NMI, su representante actual (Cricetulus migratorius), suele vivir en estepas arbustivas y praderas secas. Hay especies que pueden vivir en zonas boscosas, linderos de bosque o zonas mas abiertas, pero con desarrollo de la vegetación generalmente arbustiva, como Erinaceus europaeus (3\%), Crocidura russula (5\%) y Eliomys quercinus (2\%). Apodemus sylvaticus vive en áreas con abundante vegetación arbustiva o arbórea y Apodemus flavicollis es típicamente forestal. Aunque no hay especies estrictamente forestales entre las mencionadas anteriormente, Eliomys quercinus (2\%) y el género Apodemus (10\%), cuando abundan en el Pleistoceno, se asocian a un cierto desarrollo forestal (Chaline, 1972; Michaux \& Pasquier, 1974; Pemán, 1985; Kowalski, 2001; Sesé, 2005). Castor fiber (3\%) y Arvicola sapidus (3\%) son especies ripícolas que viven junto a ríos y arroyos con abundante vegetación, boscosa en el caso de la primera y herbácea ribereña la segunda. Microtus brecciensis (31\%), como su descendiente actual Microtus cabrerae, posiblemente vivía en suelos muy húmedos con abundante vegetación herbácea de tipo ribereño o pantanoso. En cuanto a Oryctolagus cuniculus (36\%), su hábitat ideal son dehesas con matorral y pastizales.

Excepto Cricetulus migratorius, que puede vivir en climas áridos y semidesérticos, las demás especies requieren cierto grado de humedad ambiental. Ya se han mencionado las dos especies típicamente ripícolas: Arvicola sapidus y Castor fiber, que indican la presencia de un curso de agua que podría ser importante por la presencia de esta última, así como otras especies cuyo requerimiento de vegetación necesita una cierta humedad para su desarrollo. Además, Erinaceus europaeus, extendido en prácticamente toda la Península Ibérica, no vive en las zonas más áridas de la costa mediterránea.

Prácticamente todas las especies son propias de un clima templado. Crocidura russula y el género Apodemus son además taxones termófilos, y Microtus brecciensis y Oryctolagus cuniculus son especies de clima mediterráneo.

La asociación de micromamíferos de Valdocarros indica, por lo tanto, unas condiciones paleoambientales de un clima templado, como el que debió de prevalecer a lo largo de prácticamente todo el Pleistoceno Medio en España según Sesé (1994), con cierta humedad, y un gran desarrollo de la vegetación con zonas boscosas y zonas abiertas, pero con vegetación arbustiva y herbácea, vegetación ribereña y praderas. 


\section{HAT}

La asociación faunística de micromamíferos determinada en este trabajo en el yacimiento de HAT es la siguiente:

Orden Soricomorpha GREGORY, 1910

Familia Soricidae FISCHER, 1814

Soricidae indet.

Orden Rodentia BOWDICH, 1821

Familia Gliridae MUIRHEAD, 1819 Eliomys quercinus (LINNAEUS, 1766)

Familia Muridae ILLIGER, 1811 Apodemus sp.

Familia Cricetidae FISCHER, 1817 Arvicola aff. sapidus MILLER, 1908

Microtus cf. cabrerae (GIEBEL, 1847)

Orden Lagomorpha BRANDT, 1855

Familia Leporidae FISCHER, 1817

cf. Oryctolagus sp.

La asociación de micromamíferos de este yacimiento es mucho menos rica que la del yacimiento de Valdocarros, tanto en número de restos e individuos como en número de taxones.

Tabla 2.-Distribución y abundancia de los taxones de micromamíferos del yacimiento de HAT según el NMI y el porcentaje del NMI

\begin{tabular}{lcc}
\hline Taxones & NMI & \% del NMI \\
\hline Soricidae indet. & 1 & 10 \\
Eliomys quercinus & 1 & 10 \\
Apodemus sp. & 2 & 20 \\
Arvicola aff. sapidus & 2 & 20 \\
Microtus cf. cabrerae & 2 & 20 \\
cf. Oryctolagus sp. & 2 & 20 \\
\hline Total & 10 & 100 \\
\hline
\end{tabular}

La presencia de Microtus cabrerae, aunque con reservas (determinada como Microtus cf. cabrerae), hace que se adscriba al Pleistoceno Superior, lo que es coherente con la fecha obtenida en HAT mediante luminiscencia (TL), $74+16 /-12,1$ ka BP (Panera et al., 2005).

Todas las especies de este yacimiento son comunes con las de Valdocarros, excepto Microtus cabrerae del yacimiento de HAT que se considera descendiente de Microtus brecciensis, especie presente en el yacimiento de Valdocarros.

Todos los taxones identificados viven actualmente en la zona o no muy distantes, como podría ser el caso de Microtus cabrerae.
El material de micromamíferos aparece en este yacimiento en unas condiciones muy diferentes a las del yacimiento de Valdocarros, ya que, en general, los restos fósiles están dispersos y aislados, y se trata solo de piezas dentarias que no están asociadas a ningún resto óseo craneal (excepto el fragmento mandibular sin dientes del sorícido); es decir, que no hay mandíbulas ni maxilares con su dentición como sucede, sin embargo, en el yacimiento de Valdocarros. Por otra parte, algunos dientes están erosionados, unos quizás debido al rodamiento, o por haber estado expuestos a las condiciones meteorológicas durante un tiempo, o debido a procesos posdeposicionales, y otros corroídos por la acción de jugos gástricos de predadores, probablemente de aves rapaces.

Las condiciones paleoambientales sugeridas por los micromamíferos son similares a las del yacimiento de Valdocarros. Como ya se ha dicho antes, Eliomys quercinus y el género Apodemus, cuando abundan en el Pleistoceno se asocian a un cierto desarrollo forestal, y el último taxón se considera un indicador termófilo. Arvicola sapidus es una especie ripícola que vive junto a ríos y arroyos con abundante vegetación herbácea ribereña, y Microtus cabrerae es una especie mediterránea que evita el clima eurosiberiano y que está ligada actualmente a suelos muy húmedos o encharcados con abundante vegetación, fundamentalmente de juncales, durante todo el año.

Todas las especies indican un clima templado y con cierta humedad relativa y un cierto desarrollo de la cobertura vegetal, con algunas áreas boscosas y con zonas abiertas, pero con abundante vegetación arbustiva, ribereña o de praderas.

\section{AGRADECIMIENTOS}

Queremos expresar nuestro agradecimiento a la Dirección General de Patrimonio Histórico de la Comunidad de Madrid y a TRAMSA por haber financiado los trabajos de campo, a Enrique Baquedano por haber facilitado la mesa de lavado, a José Yravedra y Primitivo Sanabria por la supervisión de los trabajos de campo, a Teresa Pérez Martínez y Pilar García Somoza por triar el concentrado procedente del lavado, a Enrique Soto por la puesta a punto de los dibujos y figuras del material de micromamíferos y situación de los yacimientos, a Josefina Barreiro y Luis Castelo del departamento de Colecciones de Vertebrados del MNCN, que nos cedieron el material actual de micromamíferos, y finalmente a Ainara Badiola y otro revisor anónimo cuyas sugerencias nos han permitido mejorar el manuscrito. 


\section{Referencias}

Aguirre, E. (1989). Vertebrados del Pleistoceno continental. In: Mapa del Cuaternario de España, Escala 1:1.000.000. Instituto Tecnológico Geominero de España, Madrid: 47-69.

Agustí, J. \& Galobart, A. (1986). La sucesión de micromamíferos en el complejo cárstico de Casablanca (Almenara, Castellón): problemática biogeográfica. Paleontologia i Evolució, 20: 57-62.

Altuna, J. (1972). Fauna de mamíferos de los yacimientos prehistóricos de Guipúzcoa. Con catálogo de los Mamíferos Cuaternarios del Cantábrico y del Pirineo Occidental. Munibe, 1-4: 464 pp.

Álvarez, M.T.; Morales, A. \& Sesé, C. (1992). Mamíferos del yacimiento del Pleistoceno Superior de Cueva Millán (Burgos, España). Estudios Geológicos, 48: 193-204. doi:10.3989/egeol.92483-4384

Andrews, P. (1990). Owls, Caves and Fossils. The University of Chicago Press, London: $231 \mathrm{pp}$.

Antunes, M.T. (1989). Castor fiber na gruta do Caldeiráo. Existência, distribuçáo e extinçáo em Portugal. Ciencias da Terra (UNL), 10: 23-40.

Arribas, O. (2004). Fauna y paisaje de los Pirineos en la Era Glaciar. Lynx. ed., Barcelona: 540 pp.

Ayarzagüena, J.; Ibáñez, J.I. \& San-Miguel, A. (1976). Notas sobre la distribución y ecología de Microtus cabrerae, Thomas, 1906. Doñana Acta Vertebrata, 3 (2): 109-112.

Ayarzagüena, J. \& López Martínez, N. (1976). Estudio filogenético y comparativo de Microtus cabrerae y Microtus brecciensis. Doñana Acta Vertebrata, 3 (2): 181-204.

Baena Preysler, J. (1992). Talleres paleolíticos en el curso final del río Manzanares. Patrimonio Arqueológico del Bajo Manzanares, 1. Universidad Autónoma de Madrid: 133 pp.

Baena Preysler, J.; Baquedano, I.; Benítez, P.; Cañaveras, J.C.; Carrión, E.; Cuartero F.; Cruz, M.; Escorza, C.M.; Lario, J.; Mazo, A.V.; Millán A.; Sánchez Moral, S.; Sanz, E.; Sesé, C.; Silva, P.G. \& Yravedra J. (2010). Síntesis: interpretación general del yacimiento de TAFESA (Madrid). In: Las huellas de nuestro pasado. Estudio del yacimiento del Pleistoceno madrileño de TAFESA (antigua TRANSFESA) (Baena Preysler, J. \& Baquedano Beltrán, I., coords.). Zona Arqueológica, 14: 189-202.

Binford, L.R. (1981). Bone: ancient men, modern myths. Academic Press, New York: 320 pp.

Binford, L.R. (1984). Butchering, sharing and the archaeological record. Journal of Anthropological Arcaheology, 3: 235-257. doi:10.1016/0278-4165(84)90003-5

Blanco, J.C. (1998). Mamíferos de España: I: Insectívoros, Quirópteros, Primates y Carnívoros de las Península Ibérica, Baleares y Canarias y II: Cetáceos, Artiodáctilos, Roedores y Lagomorfos de las Península Ibérica, Baleares y Canarias. Geoplaneta, Barcelona: 457 y 383 pp.

Bramon Planas, D. (1989). ¿Castores en el Ebro? A propósito de un texto de Yaqut sobre los Sammur de Zaragoza. Aragón en la Edad Media, 8: 133-138.
Brehm (1891). Les mammifères. Ed. Baillères et fills, Paris, t. 2: 152-162.

Cabrera-Millet, M.; López-Martínez, N. \& Michaux, J. (1982). Un exemple de lignee endemique iberoccitane, les campagnols Microtus brecciensis et Microtus cabrerae (Mammalia, Rodentia): Etude phylogenetique et contexte ecologique d'un phenomene evolutif recent. In: Actes du symposium páleontologique $G$. Cuvier (Buffetaut, E., Mazin, J.M. \& Salmon, E., eds.), Montbeliard: 69-83.

Calvo, J.P.; Goy J.L.; Pérez-González A.; Zazo, C.; Morales J.; López Martínez N.; Vegas R.; San José, M.A. \& Gallego E. (1989). Hoja n 559 (Madrid). Mapa Geológico de España 1:50.000, Serie MAGNA, IGME, Madrid.

Castells, Á. \& Mayo, M. (1993). Guía de los Mamíferos en libertad de España y Portugal. Pirámide, Madrid: $470 \mathrm{pp}$.

Chaline J. (1972). Les Rongeurs du Pléistocène Moyen et Supérieur de France. (Systématique, Biostratigraphie, Paléoclimatologie). Cahiers de Paleontologie, C.N.R.S.: 410 pp.

Chaline, J.; Baudvin, H.; Jammot, D. \& Saint Girons, M.C. (1974). Les proies des rapaces. Petits Mammifères et leur environnement. Doin ed., Paris: 141 pp.

Cuenca-Bescós, G.; Canudo, J.I. \& Laplana, C. (1995). Los arvicólidos (Rodentia, Mammalia) de los niveles inferiores de Gran Dolina (Pleistoceno Inferior, Atapuerca, Burgos, España). Revista Española de Paleontología, 10 (2): 202-218.

Faith, J.T. \& Gordon, A.D. (2007). Skeletal element abundances in archaeofaunal assemblages: economic utility, sample size, and assessment of carcass transport strategies. Journal of Archaeological Science, 34: 872-882. doi:10.1016/j.jas.2006.08.007

García García, G. (1977). Micromamíferos del yacimiento achelense de la Solana de Zamborino, Fonelas (Granada). Tesis de Licenciatura, Universidad de Granada: 99 pp.

Gil, E. (1986). Taxonomía y bioestratigrafía de Micromamíferos del Pleistoceno Medio, especialmente Roedores, de los rellenos kársticos de la Trinchera de ferrocarril de la Sierra de Atapuerca (Burgos). Tesis Doctoral, Universidad de Zaragoza: 229 pp.

Gil, E. (1996). Consideraciones bioestratigráficas sobre Allocricetus bursae (Cricetidae, Rodentia) en el Pleistoceno Inferior y Medio de Atapuerca (Burgos, España). Boletín Geológico y Minero, 107-2: 145-152.

Gil, E. (1997). Bioestratigrafía y evolución de Microtus brecciensis en los yacimientos del Pleistoceno de Atapuerca (Burgos, España). Geogaceta, 21: 113-116.

Kautenburger, R. \& Sander, A.C. (2008). Population genetic structure in natural and reintroduced beaver (Castor fiber) populations in Central Europe. Animal Biodiversity and Conservation, 31.2: 25-35.

Kowalski, K. (2001). Pleistocene rodents of Europe. Folia Cuaternaria, 72: 389 pp.

Laplana, C. \& Cuenca-Bescós, G. (1998). Precisiones sobre la sistemática de Iberomys Chaline, 1972 (Arvicolidae, Rodentia, Mammalia) del Pleistoceno inferior 
de la Sierra de Atapuerca (Burgos, España). Geogaceta, 24: 183-186.

Laplana, C. \& Cuenca-Bescós, G. (2000). Una nueva especie de Microtus (Allophaiomys) (Arvicolidae, Rodentia, Mammalia) en el Pleistoceno Inferior de la Sierra de Atapuerca (Burgos, España). Revista Española de Paleontología, 15 (1): 77-87.

Laplana, C. \& Sevilla, P. (2006). Nuevos datos sobre los micromamíferos (Roedores, Insectívoros y Quirópteros) del yacimiento Camino (Pleistoceno Superior, Pinilla del Valle, Madrid). In: Libro de Resúmenes de las XXII Jornadas de Paleontología (Fernández-Martínez, E., ed.), León: 135-137.

López-García, J.M. (2008). Evolución de la diversidad taxonómica de los micromamíferos en la Península Ibérica y cambios Paleoambientales durante el Pleistoceno Superior. Tesis Doctoral, Universitat Rovira i Virgili, Tarragona: 368 pp., XIII Láms.

López Martínez, N. (1972). Los Micromamíferos del Cuaternario de Rincón de la Victoria. Boletín de la Real Sociedad Española de Historia Natural (Geología.), 70: 223-233.

López Martínez, N. (1980 a). Los micromamíferos (Rodentia, Insectivora, Lagomorpha Chiroptera), del sitio de ocupación Achelense de Áridos-1 (Arganda, Madrid). In: Ocupaciones Achelenses en el Valle del Jarama (Arganda, Madrid) (Santonja, M.; López Martínez, N. \& Pérez-González, A., eds.). Arqueología y Paleoecología, 1. Diputación Provincial de Madrid: 161-202.

López Martínez, N. (1980 b). Análisis tafonómico y paleoecológico de los vertebrados de Áridos-1. (Pleistoceno Medio, Arganda, Madrid). In: Ocupaciones Achelenses en el Valle del Jarama (Arganda, Madrid) (Santonja, M.; López Martínez, N. \& Pérez-González, A., eds.). Arqueología y Paleoecología, 1. Diputación Provincial de Madrid: 307-320.

López Martínez, N. (1989). Revisión sistemática y biostratigráfica de los lagomorfos (Mammalia) del Terciario y Cuaternario de España. Memorias del Museo Paleontológico de la Universidad de Zaragoza, 3 (3): $343 \mathrm{pp}$.

López Martínez, N. \& Ruiz Bustos, A. (1977). Descubrimiento de dos yacimientos del Pleistoceno Medio en el karst de la Sierra Alfaguara (Granada). Síntesis estratigráfica de este período en la región Bética. Estudios Geológicos, 33: 255-265.

Made, J. van der; Aguirre, E.; Bastir, M.; Fernández Jalvo, Y.; Huguet, R.; Laplana, C.; Márquez, B.; Martínez, C.; Martinón, M.; Rosas, A.; Rodríguez, J.; Sánchez, A.; Sarmiento, S. \& Bermúdez De Castro, J.M. (2003). El registro paleontológico y arqueológico de los yacimientos de la Trinchera de Ferrocarril en la Sierra de Atapuerca. Coloquios de Paleontología, Vol. Ext. 1: 345-372.

Marquet, J.-C. (1993). Paléoenvironnement et chronologie des site du domaine atlantique français d'age Pléistocène Moyen et Supérieur d'après l'étude des rongeurs. Tesis Doctoral, Université de Bourgogne, Tours: $345 \mathrm{pp}$.
Mazo, A.V.; Sesé, C.; Ruiz Bustos, A. \& Peña, J.A. (1985). Geología y Paleontología de los yacimientos plio-pleistocenos de Huéscar (Depresión de GuadixBaza, Granada). Estudios Geológicos, 41: 467-493. doi:10.3989/egeol.85415-6726

Michaux, J. \& Pasquier, L. (1974). Dynamique des populations de Mulots (Rodentia, Apodemus) en Europe durant le Quaternaire. Premières données. Bulletin de la Société géologique de France, 7, 16, 4: 431-439.

Mitchell-Jones, A.J.; Amori, G.; Bogdanowicz, W.; Krystufek, B.; Reijnders, P.J.H.; Spitzenberger, F.; Stubbe, M.; Thissen, J.B.M.; Vohralík, V. \& Zima, J. (1999). The Atlas of European Mammals. Academic Press. T \& AD Poyser Ltd. UK, London: 484 pp.

Palomo, L.J. \& Gisbert, J. (eds.) (2002). Atlas de los Mamíferos terrestres de España. Dirección General de Conservación de la Naturaleza - SECEM - SECEMU, Madrid: $564 \mathrm{pp}$.

Palomo, L.J.; Gisbert, J. \& Blanco, J.C. (eds.) (2007). Atlas y libro rojo de los Mamíferos terrestres de España. Dirección General para la Biodiversidad. Organismo autónomo de Parques Nacionales, Madrid: 586 pp.

Panera, J. (2009). La ocupación del medio fluvial en el Paleolítico antiguo. Caracterización geoarqueológica de depósitos pleistocenos del valle del río Jarama (Madrid) y estudio tecnoeconómico de la industria lítica. Tesis Doctoral, Universidad Nacional de Educación a Distancia, Madrid: 708 pp.

Panera, J.; Pérez-González, A.; Rubio Jara, S. \& Sesé, C. (2002). Ocupación humana y medio en los inicios del Pleistoceno Superior en la Cuenca de Madrid. Resúmenes de la comunicaciones de la IV Reunión Nacional de Geoarqueología, Almazán (Soria): 72-73.

Panera, J.; Pérez-González, A.; Rubio Jara, S. \& Sesé, C. (2005). El yacimiento paleolítico de HAT en el valle del Jarama: una aportación de Cuaternario de la cuenca de Madrid al debate sobre el inicio del Paleolítico medio. In: Geoarqueología y Patrimonio en la Península Ibérica y el entorno Mediterráneo (Santonja, M., Pérez-González, A. \& Machado, M.J., eds.). ADEMA, Soria: 251-260.

Panera, J.; Rubio Jara, S.; Pérez González, A.; Rus Pérez, I.; Yravedra Sainz de los Terreros, J.; Uribelarrea del Val, D.; Ruiz Zapata, B.; Sesé, C.; Soto, E.; Farjas, M.; Torres, T. \& Ortiz Menéndez, J.E. (2008 a). El registro paleolítico de las terrazas complejas de los valles del Manzanares y Jarama. Resúmenes de ponencias y comunicaciones $5^{a}$ Jornadas de Patrimonio Arqueológico de la Comunidad de Madrid. Los primeros pobladores: arqueología del Pleistoceno, 2008, Alcalá de Henares (Madrid): 14-16.

Panera, J.; Rubio Jara, S.; Pérez-González, A. \& Uribelarrea del Val, D. (2008 b). Estudo xeoarqueolóxico das terrazas complexas dos vales Manzanares e Jarama (Madrid). In: Estudos sobre paleolítico. Homenaxe a Xosé María Álvarez Blázquez, 2 (Méndez Quintas, E., coord.). Instituto de Estudos Miñoranos. Xunta de Galicia, Gondomar: 223-233.

Panera, J.; Rubio Jara, S.; Pérez González, A.; Rus Pérez, I.; Yravedra Sainz de los Terreros, J.; Uribelarrea del 
Val, D.; Ruiz Zapata, B.; Sesé, C.; Soto, E.; Farjas, M.; Torres, T. \& Ortiz Menéndez, J.E. (2010). El registro paleolítico de las terrazas complejas de los valles del Manzanares y Jarama. Actas de las $5^{a}$ Jornadas de Patrimonio Arqueológico de la Comunidad de Madrid. Los primeros pobladores: arqueología del Pleistoceno. Museo Arqueológico Regional de la Comunidad de Madrid, Alcalá de Henares, 2008: 73-92.

Pasquier, L. (1974). Dynamique evolutive d'un sousgenre de Muridae, Apodemus (Sylvaemus). Etude biométrique des caractéres dentaires de populations fossiles et actuelles d'Europe occidentale. Tesis Doctoral, Université des Sciences et Techniques du Languedoc, Montpellier: $184 \mathrm{pp}$.

Pemán, E. (1985). Aspectos climáticos y ecológicos de los Micromamíferos del yacimiento de Erralla. Munibe, 37: 49-57.

Pérez-González, A. (1971). Estudio de los procesos de hundimiento en el valle del río Jarama y sus terrazas (nota preliminar). Estudios Geológicos, 27: 317-324.

Pérez-González, A. (1980). Geología y estratigrafía de los yacimientos de Áridos en la llanura aluvial de Arganda (Madrid). In: Ocupaciones Achelenses en el Valle del Jarama (Arganda, Madrid) (Santonja, M.; López Martínez, N. \& Pérez-González, A., eds.). Arqueología y Paleoecología , 1. Diputación Provincial de Madrid: 49-61.

Pokines, J.T. (1998). The Paleoecology of Lower Magdalenian Cantabrian Spain. BAR International Series, 713: 189 pp.

Portero, J.M.; Díaz Molina, M.; Pérez González, A.; Gallardo, J.; Aguilar, M.J., \& Leal, M.C. (1990). Hoja $\mathrm{n}^{\circ} 560$ (Alcalá de Henares). Mapa Geológico de España 1:50.000, Serie MAGNA, IGME, Madrid.

Ruiz Bustos, A. (1995). Biostratigraphy of the Continental Deposits in the Granada, Guadix and Baza Basins (Betic Cordillera). In: The Hominid and their environment during the Lower and Middle Pleistocene of Eurasia. Proceedings of the International conference of Human Paleontology (Gibert, J.; Sánchez, F.; Gibert, L. \& Ribot, F., eds.), Orce, 1995: 153-174.

Ruiz Bustos, A. \& Michaux, J. (1976). Le site préhistorique nouveau de Cullar de Baza - I (Province de Grenade, Espagne) dâge pléistocène moyen. Etude préliminaire et analyse de la fauna des Rongeurs. Géologie méditerranéenne, II (3): 173-182.

San José, M.A. (1975). Hoja n 583 (Arganda). Mapa Geológico de España 1:50.000, Serie MAGNA, IGME, Madrid.

Santonja, M.; López Martínez, N. \& Pérez-González, A. (eds.) (1980). Ocupaciones Achelenses en el Valle del Jarama (Arganda, Madrid). Arqueología y Paleoecología, 1. Diputación Provincial de Madrid: 352 pp.

Scott, G.R. \& Gibert, L. (2009). The oldest hand-axes in Europe. Nature, 461: 82-85. doi:10.1038/nature08214

Sesé, C. (1986). Insectívoros, roedores y lagomorfos (Mammalia) del sitio de ocupación achelense de Ambrona (Soria, España). Estudios Geológicos, 42: 355-359. doi:10.3989/egeol.86424-5764

Sesé, C. (1989). Micromamíferos del Mioceno, Plioceno y Pleistoceno de la cuenca de Guadix-Baza (Granada).
In: Geología y Paleontología de la cuenca de GuadixBaza. (Alberdi, M.T. \& Bonadonna, F.P., eds.). Trabajos sobre el Neógeno-Cuaternario, MNCN, CSIC, 11: $185-213$.

Sesé, C. (1994). Paleoclimatical interpretation of the Quaternary small mammals of Spain. Geobios, 27, 6: 753-767.

Sesé, C. (2005). Aportación de los micromamíferos al conocimiento paleoambiental del Pleistoceno Superior de la Región Cantábrica: Nuevos datos y síntesis. In: Neandertales Cantábricos, estado de la cuestión (Montes Barquín, R. \& Lasheras Corruchaga, J.A., eds.). Monografías del Museo Nacional y Centro de Investigación de Altamira, 20: 167-200.

Sesé, C. (2010). Micromamíferos del yacimiento del Pleistoceno Medio de TAFESA (Madrid). In: Las huellas de nuestro pasado. Estudio del yacimiento del Pleistoceno madrileño de TAFESA (antigua TRANSFESA) (Baena Preysler, J. \& Baquedano Beltrán, I., coords.). Zona Arqueológica, 14: 135-139.

Sesé, C. \& Gil, E. (1987). Los Micromamíferos del Pleistoceno Medio del complejo cárstico de Atapuerca (Burgos). In: El Hombre fósil de Ibeas y el Pleistoceno de la Sierra de Atapuerca. I. (Aguirre, E.; Carbonell, E. \& Bermúdez de Castro, J.M., eds.). Junta de Castilla y León, Consejería de Cultura y Bienestar Social, Almazán (Soria): 75-88.

Sesé, C. \& Sevilla, P. (1996). Los micromamíferos del Cuaternario peninsular español: Cronoestratigrafía e implicaciones bioestratigráficas. Revista Española de Paleontología, Nºxtraordinario: 278-287.

Sesé, C. \& Soto, E. (1981). Hallazgo de Castor fiber L. en el Cuaternario de Asturias. Nuevos datos sobre la distribución de la especie en España. Memoria del I Coloquio sobre Ecología y Biogeografía, Guadalajara, Excma. Diputación Provincial de Guadalajara: 244-248.

Sesé, C. \& Soto, E. (1988). Los Micromamíferos (Rodentia, Insectivora y Lagomorpha). In: La Cueva de Ambrosio (Almería, Spain) y su posición cronoestratigráfica en el Mediterráneo occidental (Ripoll López, S., ed.). BAR International Series, 462 (I): 157-168.

Sesé, C. \& Soto, E. (2000). Vertebrados del Pleistoceno de Madrid. In: El patrimonio paleontológico de la Comunidad de Madrid. Floras y Faunas (Morales, J.; Nieto, M.; Amezua, L.; Fraile, S.; Gómez, E.; Herráez, E.; Peláez-Campomanes, P.; Salesa, M.J.; Sánchez, I.M. \& Soria, D., eds.). Arqueología, Paleontología y Etnografía, 6: 216-243.

Sesé, C.; Soto, E. \& Pérez-González, A. (2000). Mamíferos de las terrazas del valle del Tajo: primeros datos de micromamíferos del Pleistoceno en Toledo (España central). Geogaceta, 28: 133-136.

Sesé, C. \& Soto, E. (2002 a). Vertebrados del Pleistoceno del Jarama y Manzanares. In: Bifaces y Elefantes. La investigación del Paleolítico Inferior en Madrid (Panera Gallego, J. \& Rubio Jara, S., eds.). Zona Arqueológica, 1: 318-337.

Sesé, C. \& Soto, E. (2002 b). Catálogo de los yacimientos de Vertebrados del Pleistoceno en las terrazas de los ríos Jarama y Manzanares. In: Bifaces y Elefantes. 
La investigación del Paleolítico Inferior en Madrid (Panera Gallego, J. \& Rubio Jara, S., eds.). Zona Arqueológica, 1: 430-457.

Sesé, C. \& Soto, E. (2005). Mamíferos del yacimiento del Pleistoceno Medio de Ambrona: análisis Faunístico e interpretación Paleoambiental. In: Los yacimientos paleolíticos de Ambrona y Torralba (Soria). Un siglo de investigaciones arqueológicas. Zona Arqueológica, 5: 258-280.

Soto, E. \& Sesé, C. (1987). Mamíferos del Pleistoceno del Municipio de Madrid. Estudios de Prehistoria y Arqueología Madrileñas: 11-35.

Stefen, C. (2009). Intraspecific variability of beaver teeth (Castoridae: Rodentia). Zoological Journal of the Linnean Society, 155: 926-936.

Stiner, M.C. (1994). Honor Amoung Thieves: A Zooarcheological study of Neanderthal ecology. Princeton University Press, Princeton: 447 pp.

Toni, I. \& Molero, G. (1990). Los roedores (Rodentia, Mammalia) del yacimiento cuaternario de Pinilla del Valle (Madrid). Actas de las IV Jornadas de Paleontología, Salamanca, 1988: 359-373.

Vegas, R.; Pérez-González, A. \& Míguez, F. (1975). Hoja n ${ }^{\circ} 582$ (Getafe). Mapa Geológico de España 1:50.000, Serie MAGNA, IGME, Madrid.
Veron, G. (1992). Histoire biogéographique du castor d'Europe, Castor fiber (Rodentia, Mammalia). Mammalia, 56 (1): 87-108.

Villa, P.; Soto, E.; Pérez-González, A.; Santonja, M.; Mora, R.; Parcerisas, Q.; \& Sese, C. (2005). New data from Ambrona (Spain): closing the hunting versus scavenging debate. Quaternary International, 126-128: 223-250.

Vrba, E. (1980). The significance of bovid remains as indicators of environment and predation patterns. In: Fossils in the Making (Behrensmeyer, A. K \& Hill, A., eds.). University of Chicago Press, Chicago: 247271.

Yravedra, J. (2007). Chasing carnivores. Journal of Taphonomy, 2: 135.

Yravedra, J. \& Domínguez-Rodrigo, M. (2008). The shaft-based methodological approach to the quantification of long limb bones and its relevance to understanding hominid subsistence in the Pleistocene: application to four Palaeolithic sites. Journal of Quaternary Science, 24, 1: 85-96.

Recibido el 22 de abril de 2010 Aceptado el 28 de septiembre de 2010 Publicado online el 3 de mayo de 2011 